\title{
Computational Analysis of Powered Lift Augmentation for the LEAPTech Distributed Electric Propulsion Wing
}

\author{
Karen A. Deere*, Sally A. Viken*, Melissa B. Carter ${ }^{\dagger}$, Jeffrey K. Viken ${ }^{\star}$ \\ NASA Langley Research Center, Hampton, VA 23681, USA \\ Michael R. Wiese ${ }^{\S}$ and Norma Farr ${ }^{* *}$ \\ Craig Technologies, Hampton, VA 23681, USA
}

\begin{abstract}
A computational study of a distributed electric propulsion wing with a $40^{\circ}$ flap deflection has been completed using FUN3D. Two lift-augmentation power conditions were compared with the power-off configuration on the high-lift wing ( $40^{\circ}$ flap) at a $73 \mathrm{mph}$ freestream flow and for a range of angles of attack from -5 degrees to 14 degrees. The computational study also included investigating the benefit of corotating versus counter-rotating propeller spin direction to powered-lift performance. The results indicate a large benefit in lift coefficient, over the entire range of angle of attack studied, by using corotating propellers that all spin counter to the wingtip vortex. For the landing condition, $73 \mathrm{mph}$, the unpowered $40^{\circ}$ flap configuration achieved a maximum lift coefficient of 2.3. With high-lift blowing the maximum lift coefficient increased to 5.61. Therefore, the lift augmentation is a factor of 2.4. Taking advantage of the fullspan lift augmentation at similar performance means that a wing powered with the distributed electric propulsion system requires only 42 percent of the wing area of the unpowered wing. This technology will allow wings to be 'cruise optimized', meaning that they will be able to fly closer to maximum lift over drag conditions at the design cruise speed of the aircraft.
\end{abstract}

\begin{tabular}{|c|c|c|c|}
\hline & No & nenclature & \\
\hline$C_{D}$ & drag coefficient & $\mathrm{V}$ & freestream velocity, $\mathrm{ft} / \mathrm{sec}$ \\
\hline$C_{D, H N L}$ & drag coefficient, high-lift nacelles contribution & $V_{t, \text { ratio }}$ & ratio of tip speed to freestream velocity \\
\hline$C_{D, p y l o n s}$ & drag coefficient, pylons contribution & $\mathrm{W}$ & aircraft weight, lbf \\
\hline$C_{D, T N}$ & drag coefficient, tip nacelles contribution & $\left(\mathrm{x}_{\mathrm{p}}, \mathrm{y}_{\mathrm{p}}, \mathrm{z}_{\mathrm{p}}\right)$ & coordinates for the center of the propellers \\
\hline$C_{D, \text { wing }}$ & drag coefficient, wing contribution & y & axis along the wing span, in \\
\hline$C_{L}$ & lift coefficient & $y^{+}$ & nondimensional height, first node in boundary layer \\
\hline$C_{L, e f f}$ & effective lift coefficient: $C_{L}+C_{L, p r o p}$ & Symbols & \\
\hline$C_{L, \max }$ & maximum lift coefficient & $\alpha$ & aircraft angle of attack, degrees \\
\hline$C_{L, \text { prop }}$ & lift coefficient from the contribution of & $\Delta$ & delta \\
\hline & propeller thrust in lift direction & $\rho$ & density, slugs $/ \mathrm{ft}^{3}$ \\
\hline$C_{l}$ & sectional lift coefficient & Abbreviations & \& Acronyms \\
\hline$C_{m}$ & pitching moment coefficient & BSL & Menter $k-\omega$ basic turbulence model \\
\hline$C_{p}$ & pressure coefficient & CFL & Courant-Friedrichs-Lewy number \\
\hline$c_{r e f}$ & reference chord, ft. & $\mathrm{CW}$ & clockwise \\
\hline$C_{T}$ & thrust coefficient & DEP & distributed electric propulsion \\
\hline$C_{Q}$ & torque coefficient & HL & high lift \\
\hline $\mathrm{D}$ & drag force, $\mathrm{lbf}$ & HLN & high-lift nacelles, including pylons \\
\hline $\mathrm{d}$ & propeller diameter, $\mathrm{ft}$. & KEAS & knots equivalent airspeed \\
\hline $\mathrm{h}$ & altitude, $\mathrm{ft}$. & LM & Langtry-Menter transition model \\
\hline$K_{T}$ & normalized thrust coefficient & $\max$ & Maximum \\
\hline$K_{Q}$ & normalized torque coefficient & $\mathrm{mph}$ & miles per hour \\
\hline$L^{e}$ & lift force, $\mathrm{lbf}$ & prop & propeller \\
\hline$M$ & Mach number & QCR & quadratic constitutive relation \\
\hline $\mathrm{P}$ & pressure, $\mathrm{lbf} / \mathrm{in}^{2}$ & RPM & revolutions per minute \\
\hline q & dynamic pressure, $1 \mathrm{bf} / \mathrm{in}^{2}$ & SA & Spalart-Almaras one equation turbulence model \\
\hline $\operatorname{Re}$ & Reynolds number based on $c_{r e f}$ & SARC & SA rotation and curvature correction \\
\hline S & wing reference area, $\mathrm{ft}^{2}$ & $\mathrm{hp}$ & horse power \\
\hline $\mathrm{T}$ & temperature, ${ }^{\circ} \mathrm{F}$ & SST & Menter's Shear Stress Transport model \\
\hline
\end{tabular}

\footnotetext{
* Aerospace Engineer, Configuration Aerodynamics Branch, Mail Stop 499, AIAA Senior Member.

${ }^{\dagger}$ Aerospace Engineer, Configuration Aerodynamics Branch, Mail Stop 499, AIAA Associate Fellow.

$\$$ Aerospace Engineer, Aeronautics Systems Analysis Branch, Mail Stop 442, AIAA Senior Member.

$\S$ Senior Researcher, GEOLAB, Mail Stop 128.

${ }^{* *}$ Technical Group Lead, GEOLAB, Mail Stop 128.
} 


\section{Introduction}

NASA is taking the necessary first steps to reduce the environmental impact of general aviation aircraft, and potentially, larger aircraft as batteries continue to improve. In our future, NASA envisions electrically-powered airplanes filling the skies and eliminating the use of jet fuel that pollutes our atmosphere with carbon dioxide, nitrogen oxides, hydrocarbons and soot particles [1]. Researchers at NASA investigated distributed electric propulsion (DEP) in the Leading Edge Asynchronous Propulsion Technology (LEAPTech) project as a step to replace internal combustion engines with battery-powered motors that drive high-lift and cruise propellers. Aircraft with DEP systems will allow for a smaller wing (i.e., shorter span and higher aspect ratio), lower cruise drag, and consume 5 times less energy than a baseline, aviation gas-fueled airplane [2]. To assist takeoff and landing with a smaller wing, electricallydriven, high-lift propellers are mounted on nacelles upstream of the wing leading edge to increase dynamic pressure over the wing, increasing lift. The advanced-design propellers are designed to fold smoothly onto the nacelle during cruise flight.

Since no previous DEP experiments had been conducted, a ground test experiment was designed with NASA SBIR funding. Figure 1 shows the DEP high-lift wing that was tested experimentally at the NASA Armstrong Flight Research Centeron the Hybrid-Electric Integrated Systems Testbed (HEIST) truck as part of the Leading Edge Asynchronous Propulsion Technology (LEAPTech) project. Initial computational fluid dynamics (CFD) results of the LEAPTech wing were published in reference 3. The current paper documents the results from a computational study using the FUN3D [4] Navier-Stokes CFD code for powered lift augmentation of the LEAPTech wing, assessing alternate approaches for the propeller spin rotation and various high-lift propeller combinations for blowing during powered lift. Although it would be desirable to compare the CFD results with the experimental data obtained from the HEIST test, the test data was not of sufficient quality to validate CFD data because of the uncertainty associated with this new truck-test technique. However, the LEAPTech test data was used to qualitatively compare with the CFD solutions to gain confidence that the tools could predict powered-lift increments comparable to those seen in the HEIST experiment.

\section{Configuration}

The configuration used in this report was the LEAPTech high-lift wing with a $40^{\circ}$ flap deflection and DEP system that was tested on the HEIST truck. The wing consisted of the NASA GAW-1 airfoil with a fullspan 30\% chord Fowler flap [5] and 18 propellers mounted on electric motors in nacelles upstream of the wing leading edge. The tip nacelles on the test article did not include the electric cruise motors that would be present to power the cruise propellers in a real airplane application. The LEAPTech wing has $4^{\circ}$ twist and $\alpha$ $=0^{\circ}$ is defined when the root section incidence is $5^{\circ}$. At the $\alpha=0^{\circ}$ inclination, all of the high-lift motor nacelles are at $0^{\circ}$ incidence to the freestream flow. The wing reference area is $7944.48 \mathrm{in}^{2}\left(55.17 \mathrm{ft}^{2}\right)$, reference span is $372 \mathrm{in}$., and the reference chord is $19.188 \mathrm{in}$. The moment reference center was located at the root quarter chord (6.9014 in., 0 in., 31.9185 in.).

\section{Computational Study}

Fully turbulent flow predictions of the LEAPTech wing were computed with the FUN3D NavierStokes CFD code using the Spalart-Allmaras (SA) one-equation turbulence model with rotation and curvature correction (RC) [6] and the quadratic constitutive relation (QCR) [7]. FUN3D is a node-based, finite-volume discretization, Reynolds-averaged Navier-Stokes flow solver. All of the FUN3D simulations for this study used an actuator disk representation for the high-lift propellers, with thrust and torque coefficient data used for inputs. The thrust and torque coefficient data were derived from the XROTOR [8] blade element momentum analyses. All cases were run with steady-state calculations that used a local time step pseudo-time advancement scheme. The pseudo-time advancement CFL number was ramped up from 1 to 100 over 1000 iterations for lower angles of attack and the maximum CFL was limited to 40 for the higher angles of attack.

Two approaches for the propeller spin direction were investigated for blown-wing lift augmentation, to determine which approach generated the most lift. Figure 2(a) shows the counter-rotating propeller approach, which has pairs of propellers spinning toward each other. Figure 2(b) shows the propellers all spinning in the direction opposite the wingtip vortex in the corotating propeller approach. The propeller numbers are labeled in figure 2(b). Additionally, partially-blown wing studies were investigated to understand the impact of operating fewer propellers as well as the impact of inoperable propellers on lift. 
The partially-blown configurations include corotating propellers 10 through 15 operating, corotating even propellers operating, and corotating propellers 11 through 16 operating.

\section{A. Grid Generation}

The GridTool/VGRID [9] software was used to generate the meshes for FUN3D simulations. GridTool is used to take a supplied IGES file and create the necessary points, curves, patches and grid topology (sources) to define the surface for grid generation. VGRID is a tetrahedral unstructured grid program that can either be run interactively or in a batch mode with grid spacing corresponding to the strength of user-defined sources placed in the domain. The advancing layers method [10] is used to generate the boundary layer and the advancing front is used to generate the farfield tetrahedral mesh. POSTGRID is used for additional post-processing, to close any open pockets that do not have cells and to improve the grid quality.

An unstructured, mixed element mesh was used for the FUN3D simulations. The mixed element mesh had prisms in the boundary layer and tetrahedral cells in the farfield, with pyramids to transition between the boundary layer and farfield cells. The farfield boundaries were extended to approximately 100 chord lengths away from the wing. A semispan computational model of the right half of the wing was used since all calculations were computed at $0^{\circ}$ angle of sideslip. No special patching is required within the FUN3D grid for the propellers, except the clustering of cells to resolve the flow. The clustering is accomplished in VGRID with a cylinder volume source.

A flat-plate, turbulent boundary layer calculator was used with reference chord length $\left(c_{r e f}\right)$, Reynolds number based on $c_{r e f}$, intended $y^{+}$, and an intended number of node layers within the boundary layer, to determine the inputs for VGRID of the first node height and the expansion rate of the grid. As recommended in reference 11 , the intended $y^{+}$used was 0.67 for a medium mesh resolution, and the number of node layers in the boundary layer was specified as 26 . The corresponding VGRID spacing for the first node height was $2.8 \mathrm{e}-4 \mathrm{in}$. The boundary layer specifications were good for the unblown wing because the solutions had $y^{+}$of 1 or less. The $y^{+}$values are not shown in this paper. However, for the blown-wing cases, the $y^{+}$varied with values less than 1 in the unblown region and values less than two on the wing upper surface in the blown region. Along the wing leading edge, the $y^{+}$values were less than three on the "blade up' side of the nacelle where the upwash increases the local velocity, and $y^{+}$values were less than two on the 'blade down' side of the nacelle.

An initial grid study was completed with coarse, medium and fine meshes to determine an appropriate mesh for predicting $C_{L}$. The coarse, medium and fine meshes had 35.4, 42.9, and 53.6 million total mesh points, respectively. The viscous boundary layers had 24.3, 29.3 and 35.9 million mesh points for the coarse, medium and fine meshes, respectively. The lift, drag and pitching moment coefficients for these meshes are shown in figure 3. The coefficients are similar for the fine and medium meshes, while the coarse mesh data is the outlier. The coarse mesh does not have enough grid resolution to adequately model the flow, predicting a severe, premature stall break that isn't present in the medium and fine mesh data. The wing stalls after $\alpha=2^{\circ}$ for the coarse mesh with a severe reduction of lift of $\Delta C_{L}=-0.34(10.7 \%)$, an increase in drag of $\Delta C_{D}=0.14$, and a $\Delta C_{m}=0.35$ reduction in negative pitching moment from $\alpha=2^{\circ}$ to $\alpha=$ $4^{\circ}$. Both the medium and fine meshes predict maximum lift coefficient at $\alpha=4^{\circ}$ for the angles of attack studied, however, a finer $\alpha$ scale may refine $C_{L, \max }$. The medium mesh grid was used for the remainder of this work to take advantage of fewer resources than required for the fine mesh grid. The $y^{+}$values were similar for all three meshes because the first node height did not vary between the meshes. In future blownwing CFD, care must be used when choosing a first node height to account for the increased velocity from the propellers, above the freestream value, but not restrict the first node height to a value that is so small that it hinders convergence.

\section{B. Boundary Conditions and Propeller Modeling}

A symmetry plane boundary condition is used for the semispan grids. A no-slip boundary condition was used on all solid surfaces. Riemann invariants boundary condition was used for the farfield mesh boundaries.

An actuator disk was used to simulate the high-lift (HL) propellers. There are 6 options to loading the rotor in FUN3D but the one implemented for this work was a body force based on the optimal distribution of Goldstein [12] implemented as described by Stern, Kim, and Patel [13]. Inputs for the actuator boundary condition include tip radius ( $8.79 \mathrm{in}$.), nacelle hub radius ( $2.88 \mathrm{in}$.), the location of the 
nacelle hub centers for each propeller $\left(x_{p}, y_{p}, z_{p}\right)$, the orientation of the propeller within the grid and the direction of rotation. Additionally, the ratio of tip speed to freestream velocity $\left(V_{t, \text { ratio }}\right)$, normalized thrust coefficient $\left(K_{T}\right)$ and normalized torque coefficient $\left(K_{Q}\right)$ were required for each propulsor and the values are shown in Table 1 . The $V_{t \text {,ratio }}$ was calculated with equation 1 . The torque and thrust coefficients were calculated with equations 2 and 3 using the propeller diameter (d) of $1.465 \mathrm{ft}$. The normalized torque coefficient and thrust coefficient were computed with equations 4 and 5 and used in the actuator boundary condition input file.

Table 1. Values for the actuator disk model to simulate HL propellers, $h=2300 \mathrm{ft}$.

\begin{tabular}{|l|l|l|l|l|l|l|l|l|}
\hline Description & $\mathbf{h p}$ & $\mathbf{h p} / \mathbf{p r o p}$ & $\mathbf{R P M}$ & $\mathbf{V}, \mathbf{m p h}$ & $\mathbf{T},{ }^{\circ} \mathbf{F}$ & $\boldsymbol{K}_{\boldsymbol{Q}}$ & $\boldsymbol{K}_{\boldsymbol{T}}$ & $\boldsymbol{V}_{\boldsymbol{t}, \text { ratio }}$ \\
\hline Windmilling & 23.4 & 1.3 & 3000 & 73 & 40 & 0.03330 & 0.01541 & 2.1485 \\
\hline Takeoff & 257.4 & 14.3 & 6370 & 73 & 40 & 0.04555 & 0.01764 & 4.5621 \\
\hline $\begin{array}{l}\text { Grid and Propeller } \\
\text { Rotation Study }\end{array}$ & 300.6 & 16.7 & 6147 & 73 & 60 & 0.05472 & 0.02377 & 4.3876 \\
\hline $\begin{array}{l}\text { Partial-Span } \\
\text { Blown Wing Study }\end{array}$ & varies & 16.7 & 6,771 & 60 & 60 & 0.05846 & 0.02419 & 5.3251 \\
\hline Landing & 324 & 18 & 6860 & 73 & 40 & 0.04628 & 0.01778 & 4.9130 \\
\hline
\end{tabular}

$$
\begin{aligned}
& V_{t, \text { ratio }}=\left[\pi *\left(\frac{R P M}{60}\right) * d\right] / V \\
& C_{Q}=\text { Torque } /\left[\rho\left(\frac{R P M}{60}\right)^{2} d^{5}\right] \\
& C_{T}=\text { Thrust } /\left[\rho\left(\frac{R P M}{60}\right)^{2} d^{4}\right] \\
& K_{Q}=\frac{8}{\pi^{3}} C_{Q} \\
& K_{T}=\frac{4}{\pi^{3}} C_{T}
\end{aligned}
$$

\section{Flow Conditions}

All of the solutions were computed at an altitude of $\mathrm{h}=2300 \mathrm{ft}$. to best match conditions at the NASA Armstrong Flight Research Center.

The initial computational grid study and propeller rotation study were computed with a freestream velocity of $73 \mathrm{mph}, M=0.096$, an air temperature of $\mathrm{T}=60^{\circ} \mathrm{F}$, and $R e=999,569$ ( 1 million). The partiallyblown wing study was conducted with a freestream velocity of $60 \mathrm{mph}, M=0.079$, an air temperature of T= $60^{\circ} \mathrm{F}$, and $R e=818,503$ ( 0.82 million) for various combinations of corotating propeller blowing for lift augmentation. The power setting for the grid study and the propeller rotation study was $300.6 \mathrm{hp}$ (16.7 hp/prop) at 6,147 RPM. The power setting for the partially blown wing study was $16.7 \mathrm{hp} / \mathrm{prop}$ at 6,771 RPM.

The data in figures 10 through 13 had freestream conditions of $73 \mathrm{mph}, M=0.098$, angles of attack from $-5^{\circ}$ to $14^{\circ}, \mathrm{T}=40^{\circ} \mathrm{F}$, and $R e=1,069,038$ (1.07 million). The $73 \mathrm{mph}$ speed at NASA Armstrong, corresponds to a 61 knots equivalent airspeed (KEAS) stall speed at sea level and also was close to the maximum possible speed of the HEIST truck. The solutions in figure 10 were conducted to compare with the test propeller RPM and ambient conditions of the HEIST test at AFRC. Two powered RPM settings were used that would correlate with takeoff and landing power requirements (Table 1). The high-lift propellers were permanently fixed upstream of the wing and were not folding, so it was not possible to experimentally test a power-off case. A third RPM setting was tested that represented a windmilling condition (Table 1), with just enough input power so the propellers were being driven forward by the motors and not driven by the oncoming flow. 


\section{Convergence Criteria}

The criteria used to monitor and determine solution convergence was a drop of at least two orders of magnitude for the flow solution residual. In addition, for an interval of 2,000 iterations, a solution was finished running if the standard deviation of $C_{L}$ and $C_{D}$ were less than 0.0020 . The unblown cases all converged well, with a standard deviation of less than 0.00014 for $C_{L}, 0.00002$ for $C_{D}$, and 0.00015 for $C_{m}$. The windmill-power blown cases all converged well within the stated criteria. The takeoff-power blown cases all converged within the stated criteria for $\alpha<4^{\circ}$ but the standard deviation for $C_{L}$ ranged from 0.0026 to 0.0071 , from 0.0015 to 0.0034 for $C_{D}$, and from 0.0026 to 0.0105 for $C_{m}$ at $\alpha \geq 4^{\circ}$. The landing-power blown cases all converged within the stated criteria for $\alpha \leq 8^{\circ}$, but the standard deviation for $C_{L}$ ranged from 0.0026 to 0.0046 , from 0.0020 to 0.0033 for $C_{D}$, and from 0.0053 to 0.0091 for $C_{m}$ at $\alpha=10^{\circ}$ and $\alpha=11^{\circ}$. These standard deviations at the high angles of attack with power were slightly higher than planned but were deemed acceptable near wing stall.

\section{Results}

Figure 4 shows comparisons of lift, drag, and pitching moment coefficients for the two propeller spin approaches, corotating and counter-rotating, for the blown, high-lift wing ( $40^{\circ}$ flap). The conditions are $73 \mathrm{mph}$ and a power setting of $300.6 \mathrm{hp}(16.7 \mathrm{hp} / \mathrm{prop})$ at $6147 \mathrm{RPM}$. Although the HEIST truck test was originally designed with counter-rotating propellers, these computational results indicated a larger benefit in lift coefficient over the entire range of angle of attack by using corotating propellers (fig. 4(a)). The maximum lift coefficient occurs at $\alpha=4^{\circ}$ for both rotation approaches, but the corotating propellers increase lift coefficient by $\Delta C_{L}=0.31$ compared to counter-rotating propellers. The drag coefficient is also increased by a maximum of $\Delta C_{D}=0.11$ over the range of angle of attack (fig. 4(b)), but the high-lift propellers are only used during take-off and landing operations. The advanced-design propellers will be designed to fold smoothly onto the nacelle during cruise flight. The pitching moment coefficient is more negative for the corotating propeller approach as compared to counter-rotating propellers, but the trends of $C_{m}$ with angle of attack are similar (fig. 4(c)).

Spanloading distributions of section lift coefficient $\left(c_{l}\right)$ along the span (y) can be used to further evaluate the lift coefficient data in figure 4(a). The effect of angle of attack on spanloading for the counterrotating propeller approach and the corotating propeller approach are shown in figures 5(a) and 5(b), with nacelle numbers above the spanwise location of the nacelle hubs and directional arrows indicating the propeller rotation. The spanloading for the unblown (no power) wing is also shown in both figures to emphasize the benefit of blowing on lift coefficient, with unblown wing $c_{l}$ curves well below the blown wing $c_{l}$ curves from $\mathrm{y}=22$ to $\mathrm{y}=182$, between nacelles 10 to 18 . The blown wing $c_{l}$ distributions for the counter-rotating propeller approach (fig. 5(a)) for $\alpha=0^{\circ}$ and $\alpha=4^{\circ}$ are similar, but $c_{l}$ for $\alpha=4^{\circ}$ is slightly higher than $\alpha=0^{\circ}$ from $0<\mathrm{y}<20$ and at the hub of nacelles 15 and 16. The lift coefficient drops substantially at $\alpha=8^{\circ}$ and $\alpha=9^{\circ}$ as the flow separates behind nacelles 15 and 16, from the left outer tip of propeller 15 to the hub of nacelle 16 , while the rest of the $c_{l}$ distributions are mostly similar. The blown wing $c_{l}$ distributions for the corotating propeller approach (fig. 5(b)) for $\alpha=0^{\circ}$ and $\alpha=4^{\circ}$ are also similar, but $c_{l}$ for $\alpha=4^{\circ}$ is slightly higher than $\alpha=0^{\circ}$ from $0<\mathrm{y}<15$ and at nacelle hubs 11 to 18 . The lift coefficient drops at $\alpha=8^{\circ}$ and $\alpha=9^{\circ}$, but not as much as the counter-rotating propeller approach, as the flow separates from $\mathrm{y}=140$ to $\mathrm{y}=156$, between nacelles 16 and 17 .

The effect of the propeller spin approach on spanloading is shown in figure 6 for angles of attack at $0^{\circ}, 4^{\circ}, 8^{\circ}$ and $9^{\circ}$. Propeller 'blade up' locations are defined as regions where the blade is moving upward at the wing leading edge, which is to the left side (pilot's view) of nacelle 10 and between nacelles 11 and 12 , 13 and 14, 15 and 16, and 17 and 18 for the counter-rotating propeller approach, and to the left side (pilot's view) of all the nacelles for the corotating propeller approach. Propeller 'blade down' locations are defined as regions where the blade is moving downward at the wing leading edge, which is between nacelles 10 and 11,12 and 13, 14 and 15, 16 and 17 and to the right side (pilot's view) of nacelle 18 for the counter-rotating propeller approach, and to the right side of all the nacelles for the corotating propeller approach. In figure 6 for angles of attack $0^{\circ}$ and $4^{\circ}$, the counter-rotating propeller approach has higher $c_{l}$ in the 'blade up' regions due to upwash from two propellers, rather than from one propeller in the corotoating approach. However, the counter-rotating propeller approach has much lower $c_{l}$ than corotating propellers in the 'blade down' regions. Again, at angles of attack of $8^{\circ}$ and $9^{\circ}$, the counter-rotating propeller approach has a separated flow region between approximately $\mathrm{y}=106 \mathrm{in}$. to $\mathrm{y}=140 \mathrm{in}$, , which is between the inboard tip of propeller 15 and nacelle hub 16 (figs. 6(c) and 6(d)), which results in a large loss of lift (fig. 4(a)), an increase in drag (fig. 
4(b)), and a shift in pitching moment (fig. 4(c)). The separated flow region for the corotating propeller approach is slightly more outboard, at a span location between nacelle hubs 16 and 17, than counter-rotating propeller approach, and the $c_{l}$ in this region is still as high as the counter-rotating propellers (figs. $6(\mathrm{c})$ and 6(d)), so the loss of lift is not as severe for the corotoating propeller approach.

To further visualize the effects of blowing from each propeller spin approach, the pressure coefficient on a plane through the wing three inches back from the leading edge, and on the upper surface of the wing, for the maximum lift coefficient case at $\alpha=4^{\circ}$, is shown in figures 7 and 8 , respectively. The white regions in figure 7 represent the wing and nacelles geometry. The nacelles are labeled 10 to 18 in both figures. The regions of 'blade up' are easily visualized with red contours between pairs of nacelles for the counter-rotating propeller approach in both figures. The increased lift with the corotating propeller approach results from higher negative pressure coefficient values over the full span of the wing upper surface (fig. 8(b)), as opposed to regions of higher negative pressure coefficient only occurring between the pairs of counter-rotating propellers (fig. 8(a)). There is a coupling of alternating upwash and downwash changes between pairs of propellers with the counter-rotating propeller approach. Based on the improved lift with corotating propellers, the project decided to proceed with the corotating propeller approach for the remainder of the HEIST truck test, and with future wing designs.

A partial-span blowing scenario study was conducted. The LEAPTech wing had full-span blowing implemented. It was known that the X-57 Maxwell configuration would not have blowing in the wing-tip region, so the performance of inboard blowing only was of interest. As a failsafe mechanism, blowing motors can be installed on a double bus electrical system. It was of interest to document the degradation in high-lift augmentation if one electrical bus would fail. Finally, the sensitivity to the spanwise location of the blowing region was investigated. Figure 9 shows the comparisons of upper-surface pressure coefficient for the partially-blown wing study at $60 \mathrm{mph}, \alpha=4^{\circ}$, and a power setting of $16.7 \mathrm{hp} / \mathrm{prop}$ at $6,771 \mathrm{RPM}$ for each of the corotating propellers that are operating. In this study, all of the powered-lift configurations were propellers corotating in a direction opposite of the wing-tip wake vortex. A table of lift, drag, and pitching moment coefficients is also shown for the following blown configurations: (a) all propellers (10-18) operating, (b) partially-blown wing with propellers 10 through 15 operating, (c) partially-blown wing with even-numbered propellers operating, and (d) partially-blown wing with propellers 11 through 16 operating. The case where all of the propellers are operating generates the most lift with $C_{L}=6.422$ and pressure coefficient reaching $C_{p}$ of -13 along the full span in the blown-wing region (fig. 9(a)). The cases where three of the propellers are not operating, 10 to 15 corotating (fig. 9(b)) or 11 to 16 corotating (fig. 9(d)), both achieve a HL coefficient of $C_{L}=5$, but reduced from $C_{L}=6.422$ as the blown-wing region shrinks. The drop in $C_{L}$ compared to all propellers operating is a result of less blowing along the span and a smaller region of pressure coefficient values reaching at least $C_{p}=-13$ along the leading edge. The even-numbered propellers operating still have a HL coefficient of $C_{L}=4.574$ with regions of upwash on the inboard side of the evennumbered propellers creating a $C_{p}$ peak suction of -13 (fig. 9(c)), but lift is substantially lower than operating all the propellers. The partially blown wing results in 22 to 29 percent reduction in lift compared to the fully-blown wing with all propellers operating. These results emphasize the need for system redundancy to avoid a substantial penalty in lift from a partially blown wing due to motor or propeller failure. In the partially-blown wing case with even-numbered propellers operating, the lift is reduced by $29 \%$. This means that compared to the fully-blown wing case, if the original stall speed was 61 KEAS, then a partially-blown wing case with even-numbered propellers operating would only have a stall speed of 72 KEAS. Future studies might investigate the additional power required for the partially-blown wing operable propellers to achieve the lift of the fully-blown wing with all propellers operable.

Runs were conducted to compare with the test propeller RPM and ambient conditions of the HEIST test at the NASA Armstrong Flight Research Center. Two powered RPM settings were used that would correlate with a takeoff and landing power requirement. The high-lift propellers were permanently fixed upstream of the wing leading edge on the nacelles and were not folding, so it was not possible to experimentally test a power-off case. A third RPM setting was tested that represented a windmilling condition, with just enough input power so the propellers were being driven forward by the motors and not driven by the oncoming flow. A comparison of lift, drag and pitching moment coefficients between unblown, windmill power, takeoff power, and landing power for the high-lift wing with corotating propellers at 73 $\mathrm{mph}$ is shown in figure 10. The maximum lift coefficient unblown is $C_{L, \max }=2.318$ at $\alpha=1^{\circ}$. The maximum lift coefficients of $C_{L, \max }=5.252$ at takeoff power $(257.4 \mathrm{hp})$ and $C_{L, \max }=5.611$ at landing 
power (324 hp) both occurred at $\alpha=4^{\circ}$. Therefore, the maximum lift augmentation, $C_{L, \max }$ from the unblown wing (2.318) to the blown wing (5.611), is a factor of 2.42. The blowing lift augmentation does come with an increase in drag (fig. $10(\mathrm{~b})$ ), from $C_{D}=0.3209$ to $C_{D}=1.0443$ at $\alpha=4^{\circ}$, for example. The blowing lift augmentation also comes with a large impact on pitching moment (fig. 10(c)), from $C_{m}=-1.720$ to $C_{m}=-4.894$ at $\alpha=4^{\circ}$, for example. In general, there is a fairly small change in pitching moment coefficient at each power condition over the range of angle of attack for the data shown. Note the pitching moment reference center is located at the root chord and not the mean aerodynamic chord of the wing.

A comparison of the pressure coefficient contours between unblown, blown with takeoff power, and blown with landing power is shown in figure 11 at $73 \mathrm{mph}$ and $\alpha=4^{\circ}$. The contours shown on a spanwise plane through the wing is located 8 inches back from the wing leading edge. This figure shows much higher negative pressures over the wing for blown conditions that cause increased dynamic pressure, which is the benefit of the DEP system. Without lift augmentation (unblown), the lowest pressure coefficient above the wing in the spanwise plane is approximately $C_{p}=-1.5$ (fig. 11(a)). With lift augmentation, the region of suction above the wing in the spanwise plane is substantially increased over most of the wingspan (out to nacelle 16) at takeoff power (fig. 11(b)), and to a further spanwise extent (out to nacelle 18) for the landing power (fig. 11(c)). Figure 12 shows the comparison of surface pressure coefficient between the unblown wing and the two blown-wing conditions at various span locations along the high-lift wing at 73 mph and $\alpha=4^{\circ}$. Figure 12 also shows the locations of the span stations on the wing (with black text) and the nacelles are numbered in red. The pressure coefficient plots further show the lift augmentation illustrated by the area between the higher negative pressures for the blown wing (red and blue curves) and the lower negative pressures on the unblown wing (green curve). It is interesting that at eight of the ten stations shown, the peak pressures on the leading edge are greater for the takeoff power $(257.4 \mathrm{hp})$ than the landing power (324 hp), because the opposite is expected due to a greater lift coefficient for the landing power condition. However, there is more lift generated over the aft upper wing surface and on the flap for the landing power (red), compared to the takeoff power (blue), as shown by higher negative pressures. One explanation could be that the flow through the propeller gets straightened, effectively lowering the angle of attack, but the higher power setting yields a higher dynamic pressure (q) above the wing to generate more lift. Figure 12(h) shows the difference in pressures just outside of nacelle 16 at $\mathrm{y}=145.8 \mathrm{in}$. where the takeoff power solution has a much lower and flat $C_{p}$ distribution than the landing power that was also viewed in figures 11(b) and 11(c). The unpowered condition looks separated downstream of the leading edge at $y=145.8$ in. (fig. 12(h)) and there appears to be an overall loss of lift in the spanwise region between nacelles 16 and 17 in the pressure contour plot (fig. 11(a)).

Taking advantage of the full-span lift augmentation at similar takeoff and landing performance means that a wing powered with the DEP system could be $42 \%$ of the wing area of the unpowered wing. This technology will allow wings to be 'cruise optimized', meaning that they will be able to fly closer to the maximum lift to drag ratio $\left(L / D_{\max }\right)$ conditions at the design cruise speed of the aircraft. A comparison of spanwise lift coefficient between maximum landing power (18 hp/prop) and no power, for the high-lift wing ( $40^{\circ}$ flap) is shown in figure 13 . The benefit of DEP is clear in the increased sectional lift coefficient with high-lift blowing power, as compared to the lift coefficient of the unblown wing. Sectional lift coefficients greater than 7.5 are computed in the blowing region. The peaks and valleys in the powered sectional lift coefficient curve results from the propellers creating areas of increased upwash and downwash across the span that result in higher and lower lift on the wing.

\section{Conclusions}

A computational study of a distributed electric propulsion high-lift wing with a $40^{\circ}$ flap deflection has been completed using FUN3D. The distributed electric propulsion wing in this study was tested experimentally on the Hybrid-Electric Integrated Systems Testbed truck at the NASA Armstrong Flight Research Center.

The computational study included three lift-augmentation power conditions of the high-lift wing in $73 \mathrm{mph}$ freestream flow, in addition to the unblown wing without lift augmentation. The angle of attack ranged from -5 degrees to 14 degrees for various portions of the computational study.

The computational study also included investigating the spin approach of the propellers, corotating or counter-rotating. The corotating propeller approach has all of the propellers spinning in a direction that counters the wingtip vortex, while the counter-rotating propeller approach has pairs of propellers spinning toward each other. The computational results indicate a larger benefit in lift coefficient over the entire range 
of angle of attack, from -6 degrees to 9 degrees, by using corotating propellers. A maximum lift coefficient occurred at 4 degrees angle of attack for both rotation approaches, but the corotating propeller approach increased lift coefficient by 0.31 at 4 degrees angle of attack.

At $73 \mathrm{mph}$, the high-lift wing with $40^{\circ}$ flap deflection achieves a maximum lift coefficient of 2.3 without high-lift blowing. Using the corotating propeller approach, the maximum lift coefficient is 5.25 with high-lift blowing at takeoff power, and 5.61 with high-lift blowing at landing power. Therefore, the lift augmentation is a factor of 2.4. The blown-wing lift augmentation does come with an increase in drag, however, the lift augmentation occurs during takeoff and landing, and thus, drag is improved during cruise when the high-lift props are not operating and fold smoothly onto the nacelles as intended. The blowing lift augmentation also comes with a large impact on pitching moment but there is a fairly small change in pitching moment coefficient for each power condition over the range of angle of attack.

Taking advantage of the fullspan lift augmentation at similar performance means that a wing powered with the DEP system could be $42 \%$ of the wing area of the unpowered wing. This technology will allow wings to be 'cruise optimized', meaning that they will be able to fly closer to $L / D_{\max }$ conditions at the design cruise speed of the aircraft.

\section{References}

1. Brasseur, G. P.; and Gupta, M: "Impact of Aviation on Climate, Research Priorities," American Meteorological Society, pp. 461-463, April 2010.

2. Borer, Patterson, Viken, Moore, Clarke, Redifer, Christie, Stoll, Dubois, Bevirt, Gibson, Foster, Osterkamp: "Design and Performance of the NASA SCEPTOR Distributed Electric Propulsion Flight Demonstrator," AIAA 2016-3920, 13-17 June 2016.

3. Stoll, A. M.: "Comparison of CFD and Experimental Results of the LEAPTech Distributed Electric Propulsion Blown Wing," AIAA 2015-3188, 22-26 June 2015.

4. Biedron, R. T.; Carlson, J. R.; Derlaga, J. M.; Gnoffo, P. A.; Hammond, D. P.; Jones, W. T.; Kleb, B.; LeeRausch, E. M.; Nielsen, E. J.; Park, M. A.; Rumsey, C. L.; Thomas, J. L.; and Wood, W. A.: "FUN3D Manual: 13.0," NASA TM-2016-219330.

5. Wentz, W.H., Jr.; and Setharam, H. C.: "Development of a Fowler Flap System for a High Performance General Aviation Airfoil,” NASA Contractor Report CR-2443, December 1974.

6. Shur, M. L., Strelets, M. K., Travin, A. K., Spalart, P. R.: "Turbulence Modeling in Rotating and Curved Channels: Assessing the Spalart-Shur Correction," AIAA Journal Vol. 38, No. 5, 2000, pp. 784-792.

7. Spalart, P. R.: "Strategies for Turbulence Modelling and Simulation," International Journal of Heat and Fluid Flow, Vol. 21, 2000, pp. 252-263.

8. Drela, M., and Youngren, H.: XROTOR Download Page, http://web.mit.edu/drela/Public/web/xrotor/, accessed 6 May 2014.

9. Pirzadeh, S.: "Advanced Unstructured Grid Generation for Complex Aerodynamics Applications," AIAA 2008-7178, 26 $6^{\text {th }}$ AIAA Applied Aerodynamics Conference, August 2008.

10. Pirzadeh, S.: "Three-dimensional unstructured Viscous Grids by the Advancing-Layers Method," AIAA Journal, Vol. 34, No. 1, January 1996, pp. 43-49.

11. " $2^{\text {nd }}$ AIAA CFD High Lift Prediction Workshop Gridding Guidelines,” http://hiliftpw.larc.nasa.gov, https:/hiliftpw.larc.nasa.gov/Workshop2/GriddingGuidelines-HiLiftPW2-v2.pdf, March 2013.

12. Goldstein, S.: "On the Vortex Theory of Screw Propellers," Proceeding of the Royal Society of London A: Mathematical, Physical and Engineering Sciences, vol. 792, no. 123, Apr. 1929, pp. 440-465.

13. Stern, F.; Kim, H. T.; and Patel, V. C.: "A Viscous-Flow Approach to the Computation of Propeller-Hull Interaction,” Journal of Ship Research, vol. 32, no. 4, Dec. 1988, pp. 246-262. 


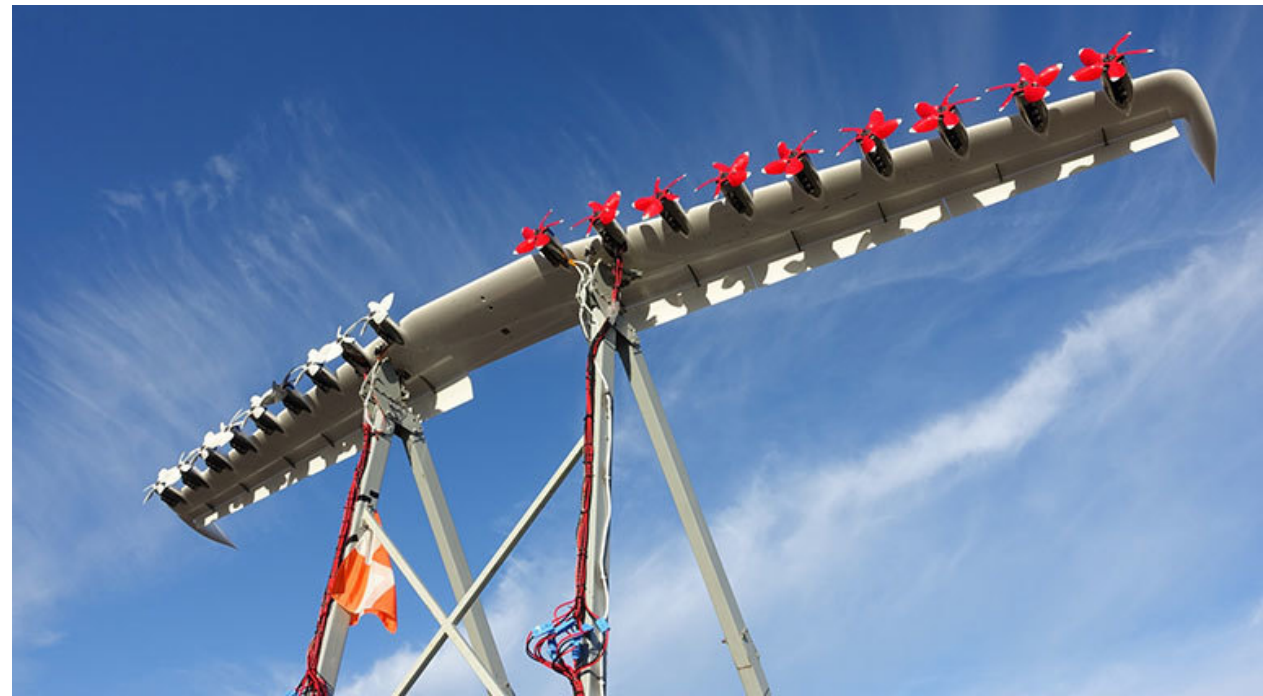

Figure 1. The DEP high-lift wing tested at NASA Armstrong on the Hybrid-Electric Integrated Systems Testbed (HEIST) truck.

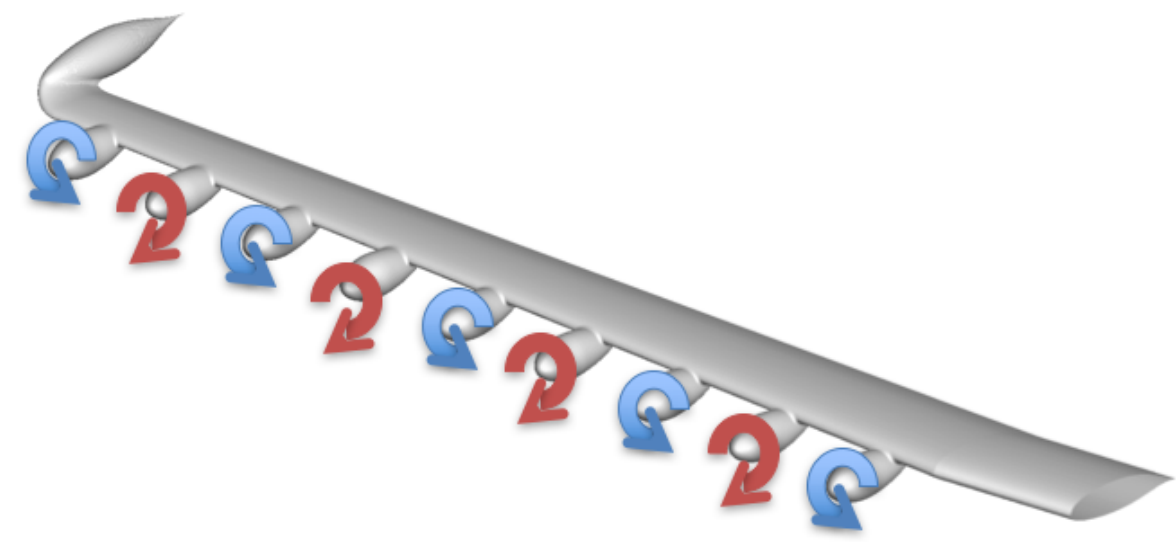

(a) Counter-rotating propellers on the right semispan wing

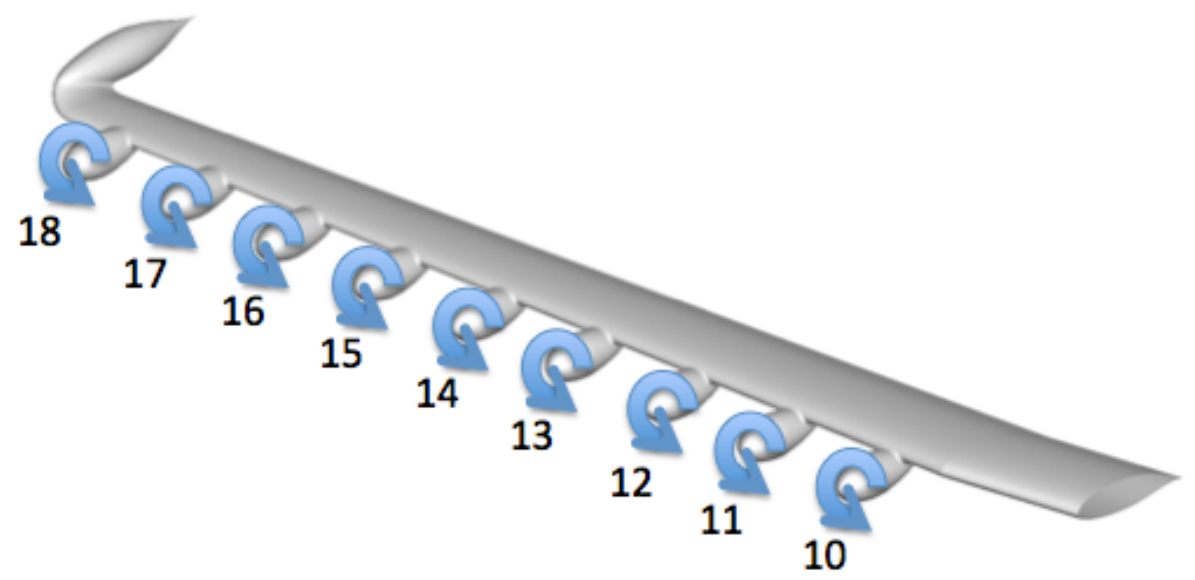

(b) Corotating propellers on the right semispan wing

Figure 2. Illustration of two approaches for the propeller spin direction. 


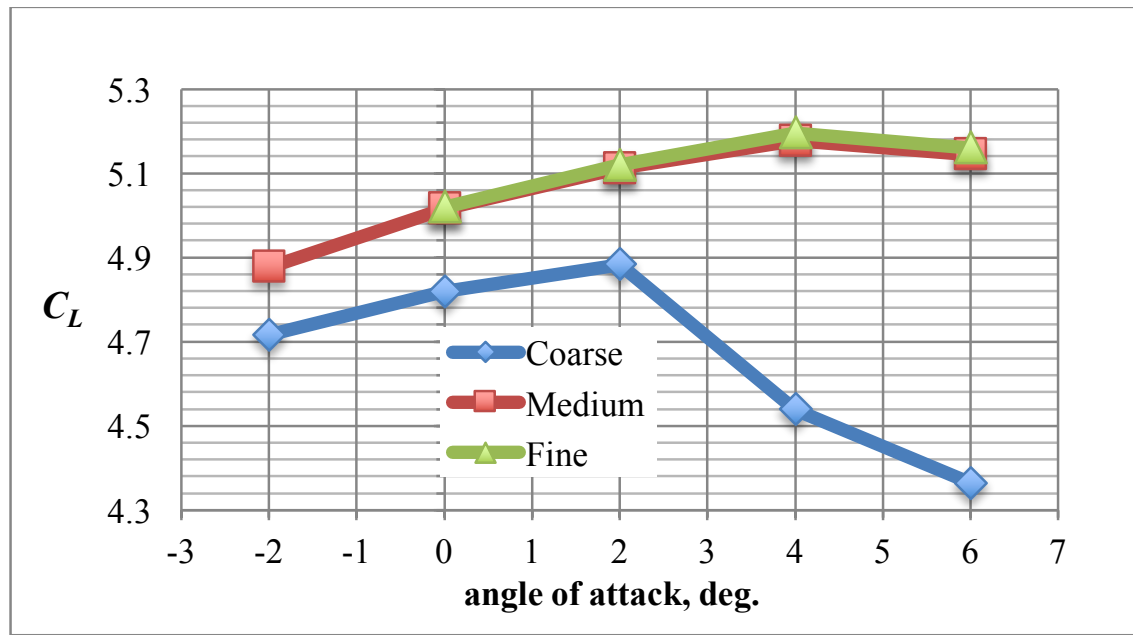

(a) Lift coefficient

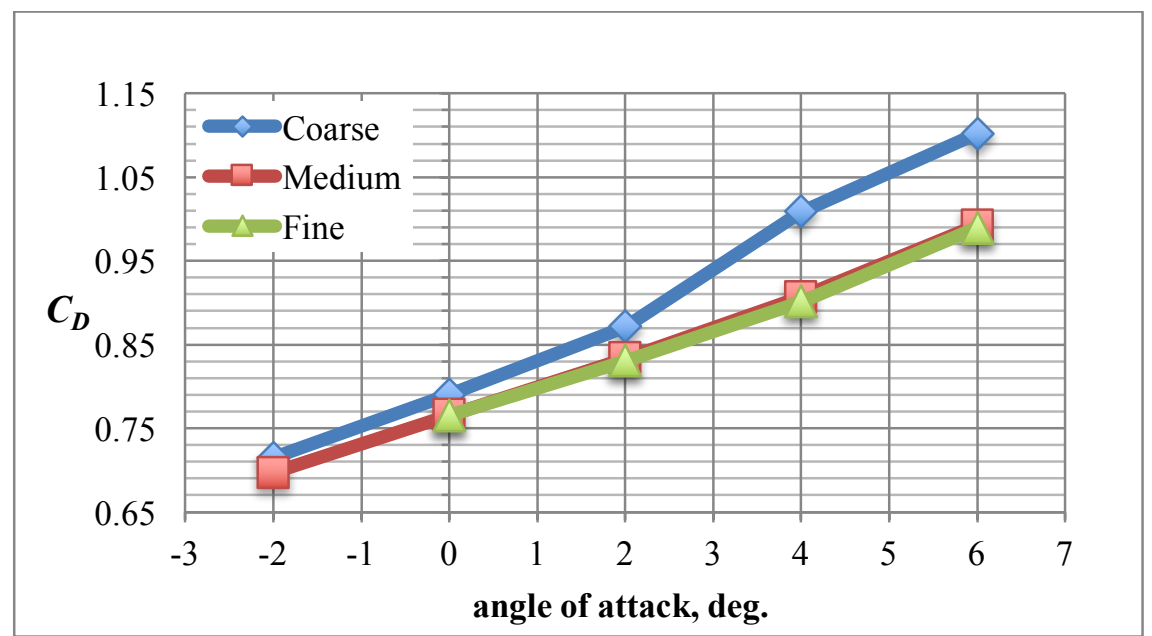

(b) Drag coefficient

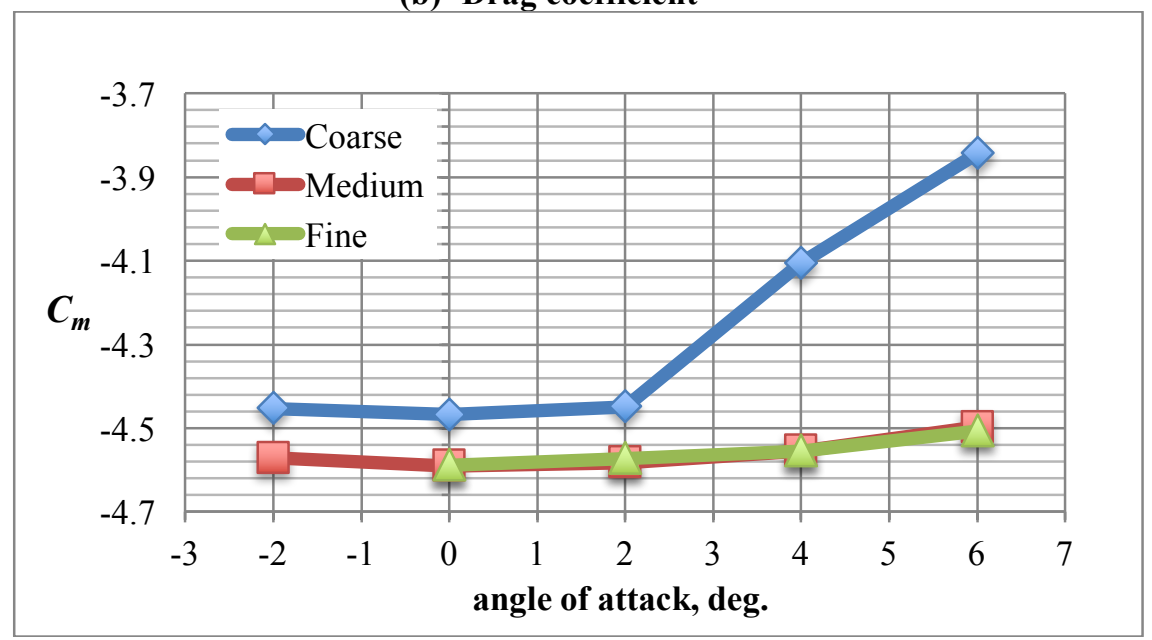

(c) Pitching moment coefficient

Figure 3. Grid study for the high-lift wing $\left(40^{\circ}\right.$ flap) at $73 \mathrm{mph}, M=0.096, R e=1 \mathrm{million}, \mathrm{h}=\mathbf{2 3 0 0} \mathrm{ft}$, $\mathrm{T}=60^{\circ} \mathrm{F}$, and $300.6 \mathrm{hp}(16.7 \mathrm{hp} / \mathrm{prop}, 6147 \mathrm{RPM})$. 


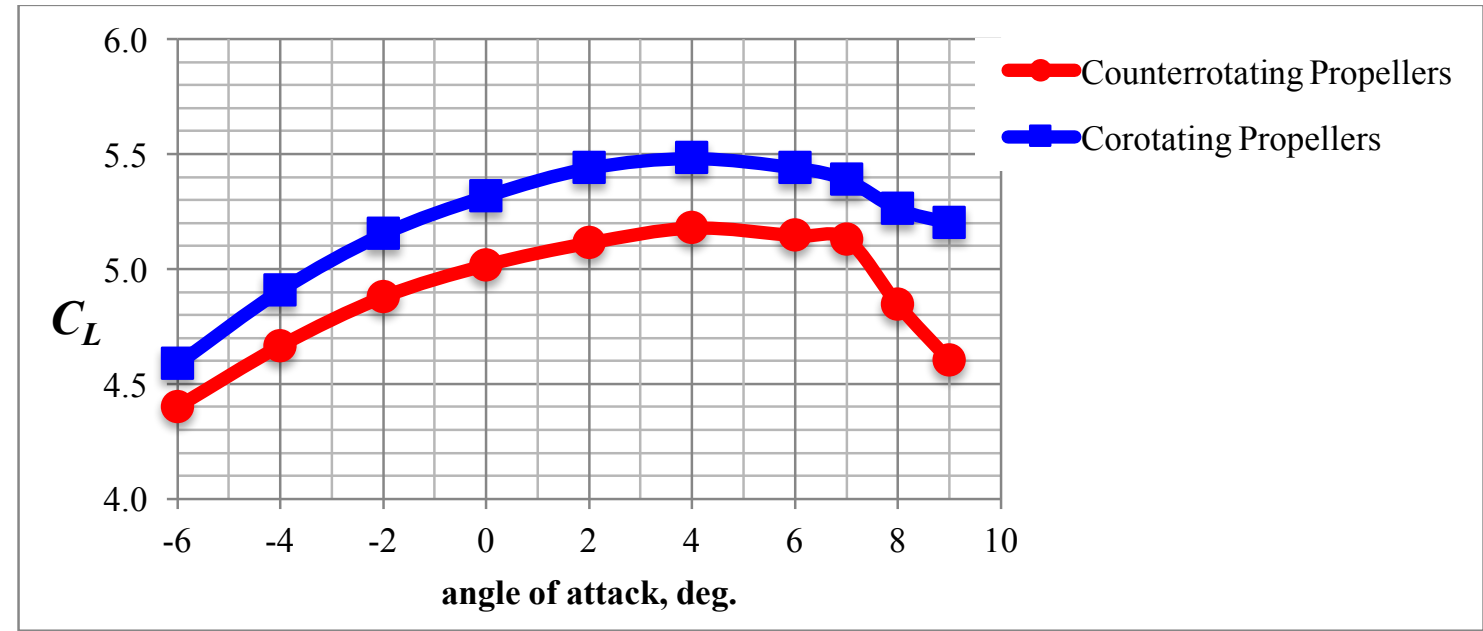

(a) Lift coefficient

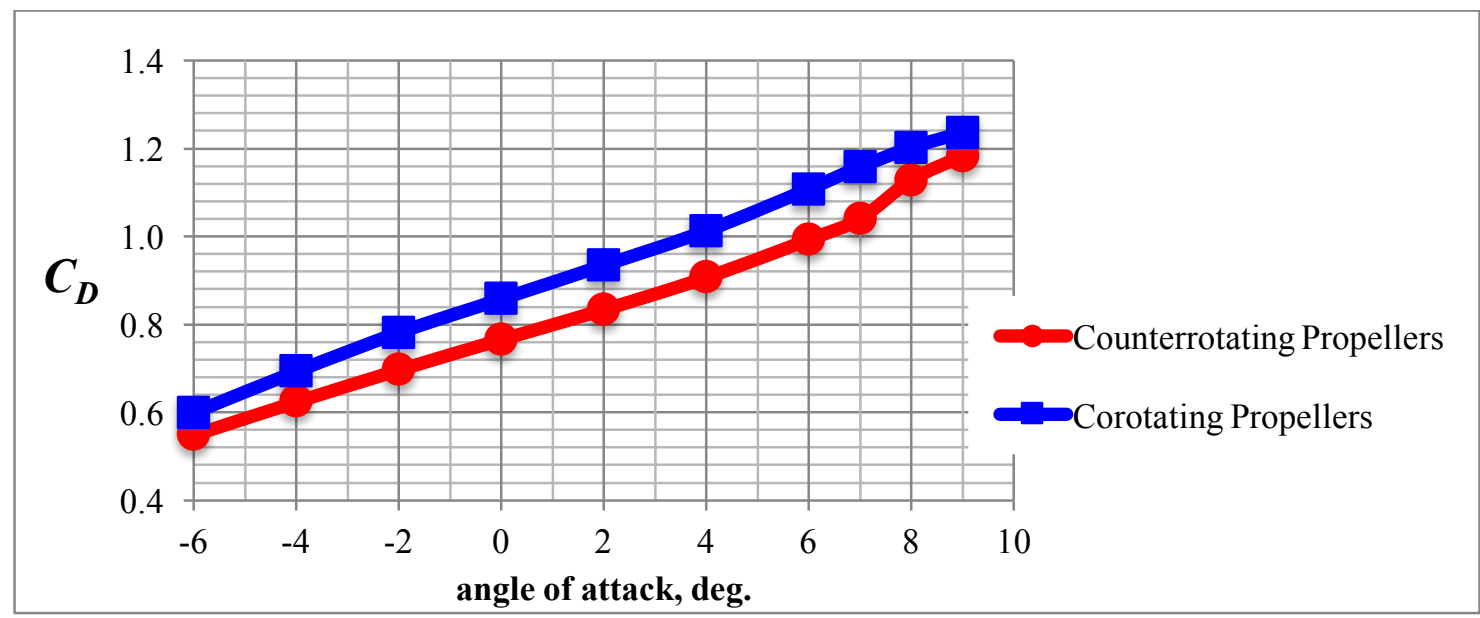

(b) Drag coefficient

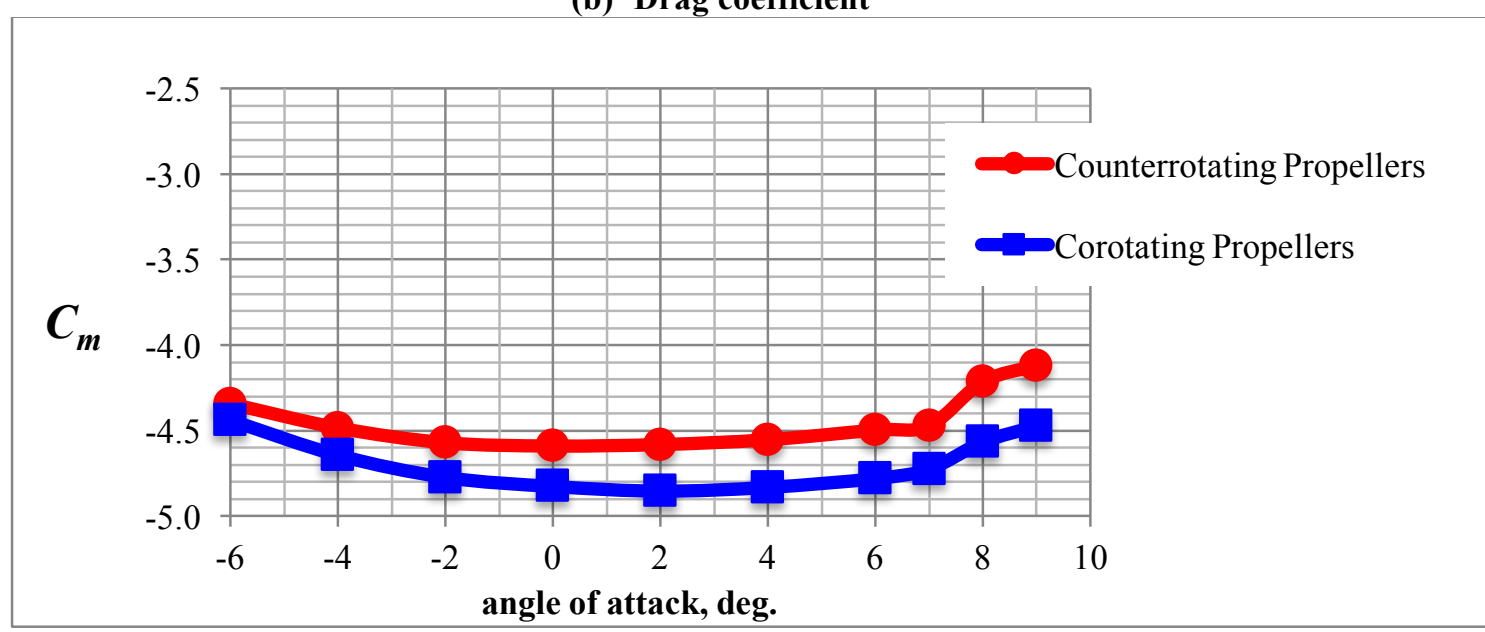

(c) Pitching moment coefficient

Figure 4. The comparison of lift, drag and pitching moment coefficient between propeller spin direction approaches for the blown, high-lift wing $\left(40^{\circ}\right.$ flap $)$ at $73 \mathrm{mph}, M=0.096, R e=1 \mathrm{million}$, $\mathrm{h}=2300 \mathrm{ft}, \mathrm{T}=6^{\circ} \mathrm{F}$, and $300.6 \mathrm{hp}(16.7 \mathrm{hp} / \mathrm{prop}, 6147 \mathrm{RPM})$. 


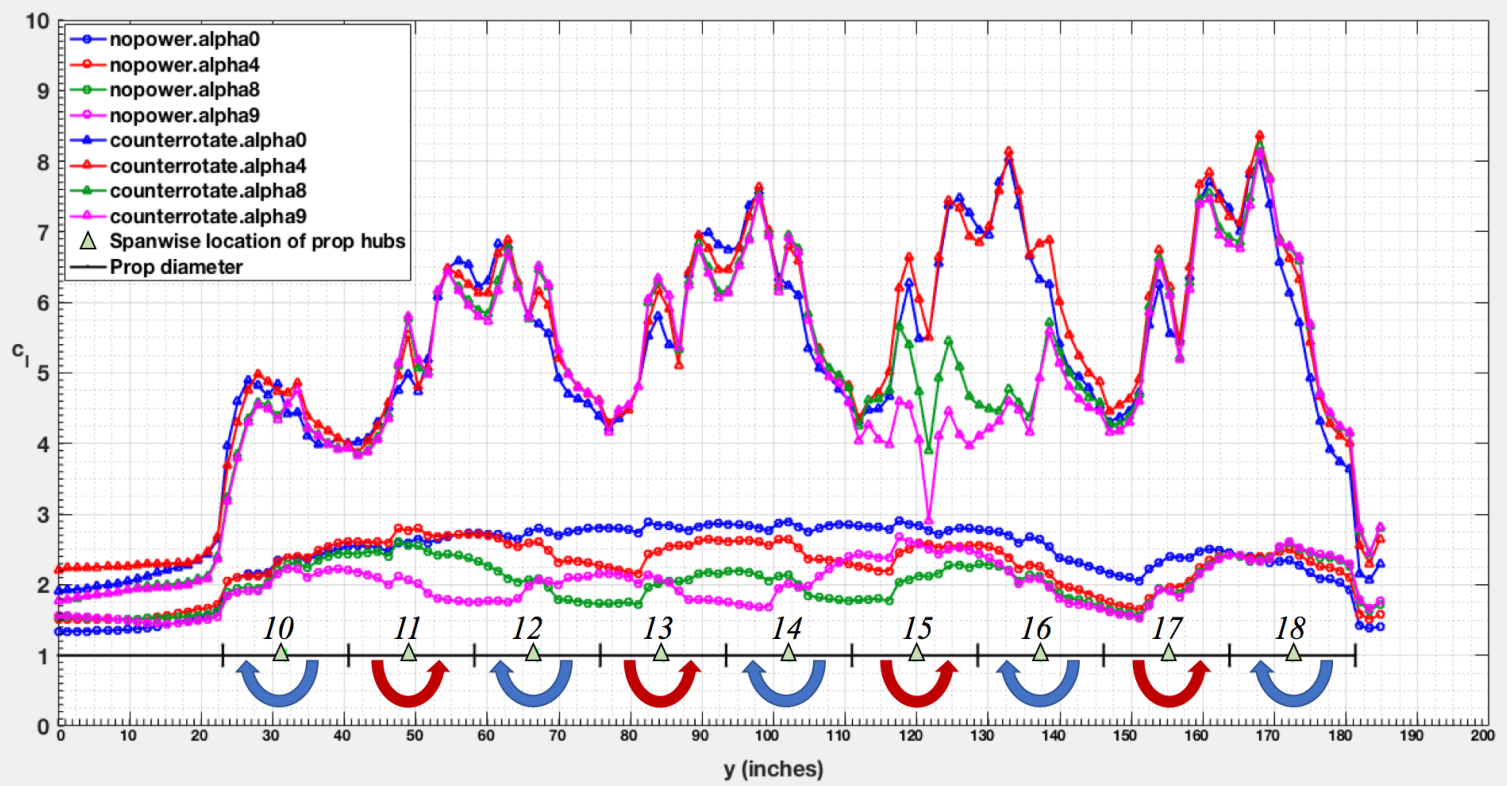

(a) counter-rotating propeller approach

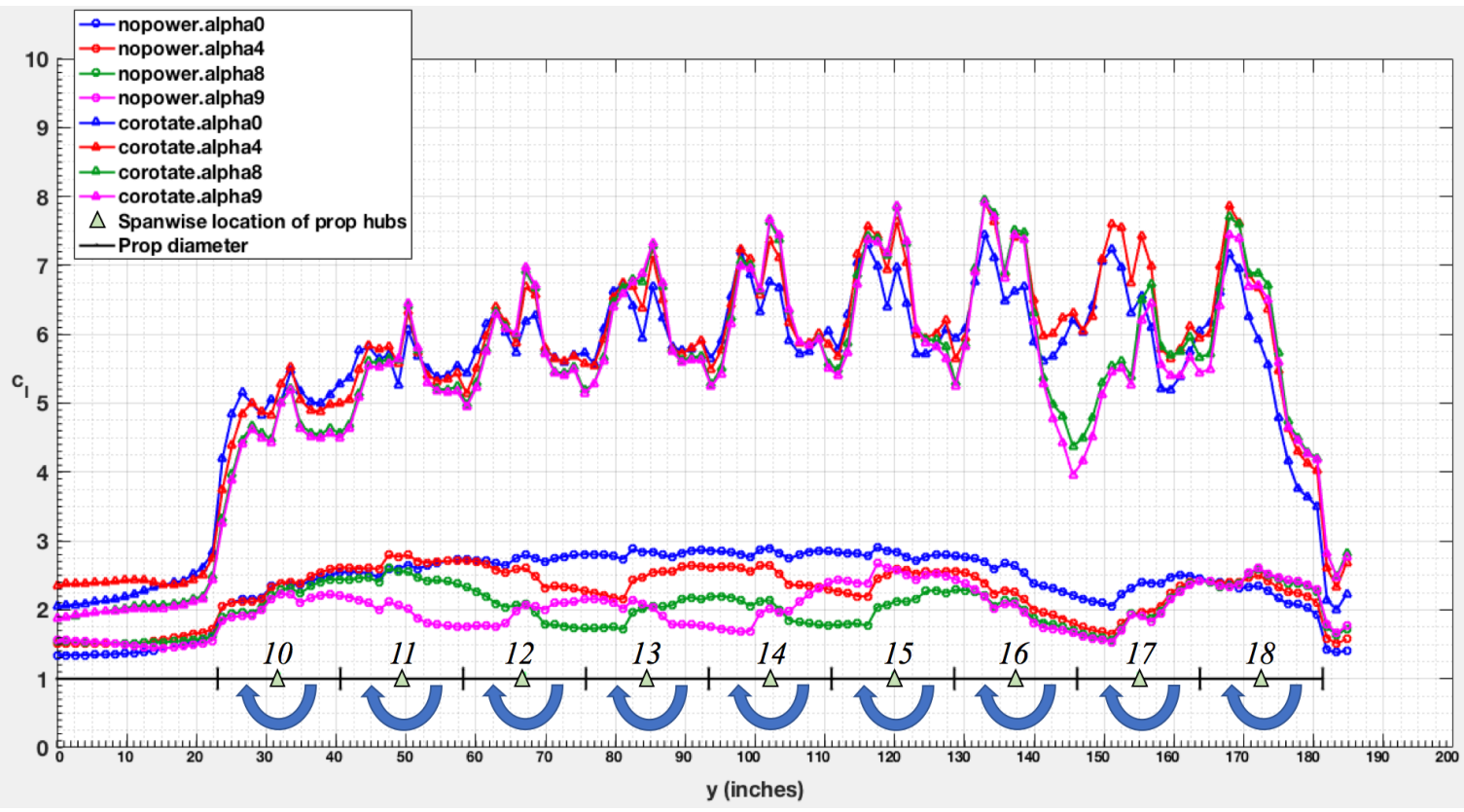

(b) corotating propeller approach

Figure 5. The effect of angle of attack on spanloading for each propeller spin direction approach, for the blown, high-lift wing $\left(40^{\circ}\right.$ flap) at $73 \mathrm{mph}, M=0.096, R e=1$ million, $\mathrm{h}=2300 \mathrm{ft}, \mathrm{T}=60^{\circ} \mathrm{F}$, and $300.6 \mathrm{hp}(16.7 \mathrm{hp} / \mathrm{prop}, 6147 \mathrm{RPM})$. 


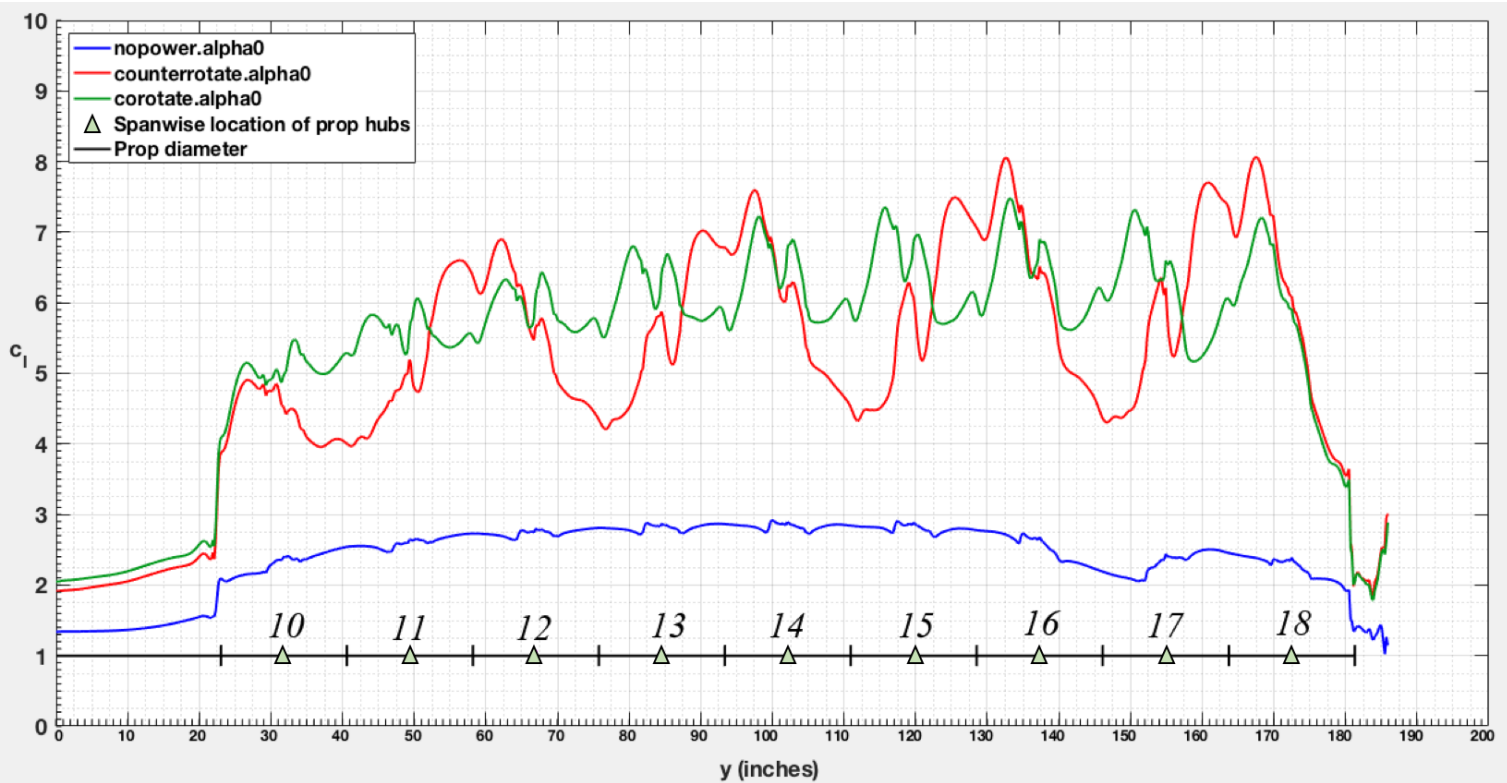

(a) $\quad \alpha=0^{\circ}$

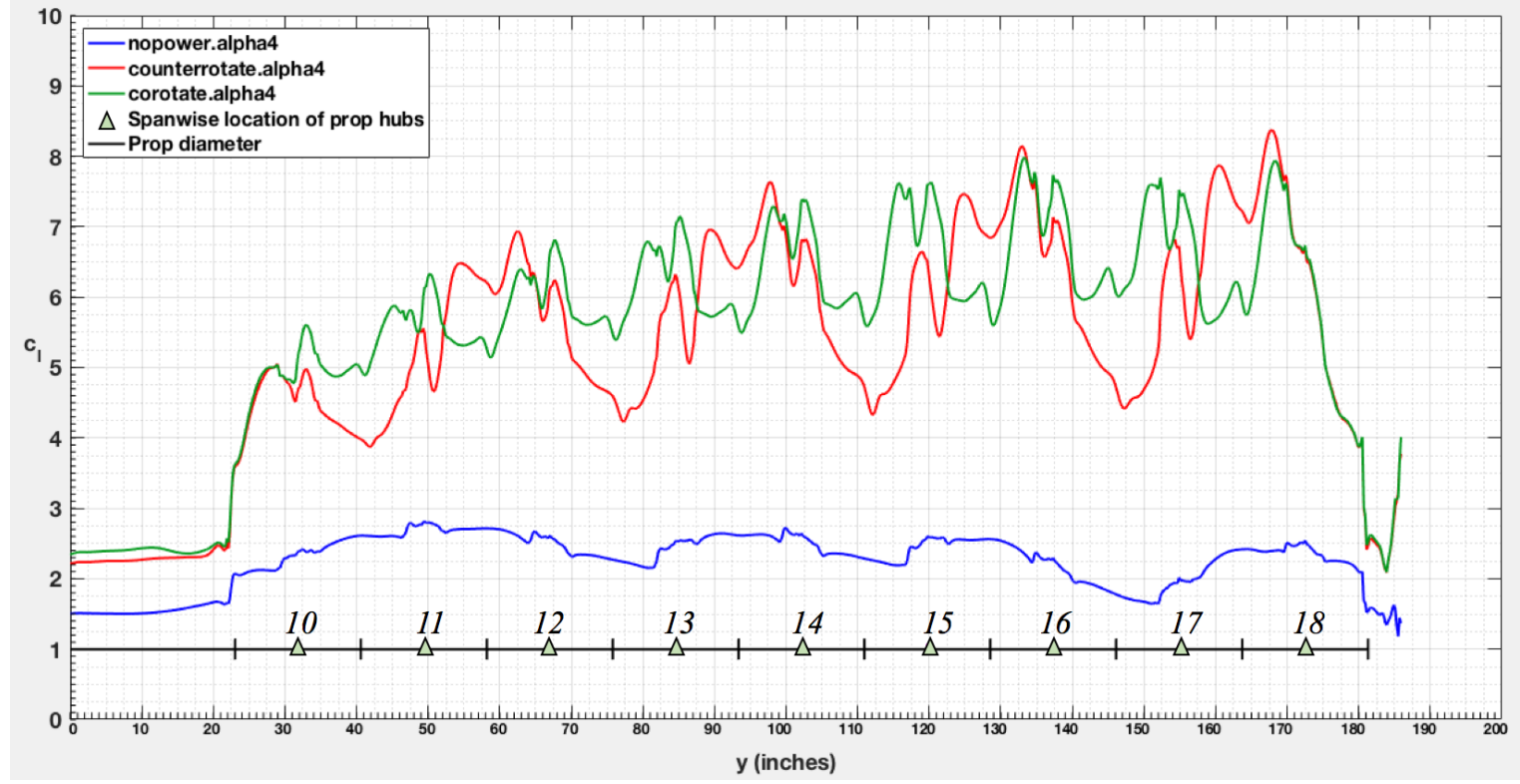

(b) $\quad \alpha=4^{\circ}$

Figure 6. The effect of propeller spin direction approach on spanloading at four angles of attack for the blown, high-lift wing $\left(40^{\circ}\right.$ flap) at $73 \mathrm{mph}, M=0.096, R e=1$ million, $\mathrm{h}=2300 \mathrm{ft}, \mathrm{T}=60^{\circ} \mathrm{F}$, and $300.6 \mathrm{hp}(16.7 \mathrm{hp} / \mathrm{prop}, 6147 \mathrm{RPM})$. 


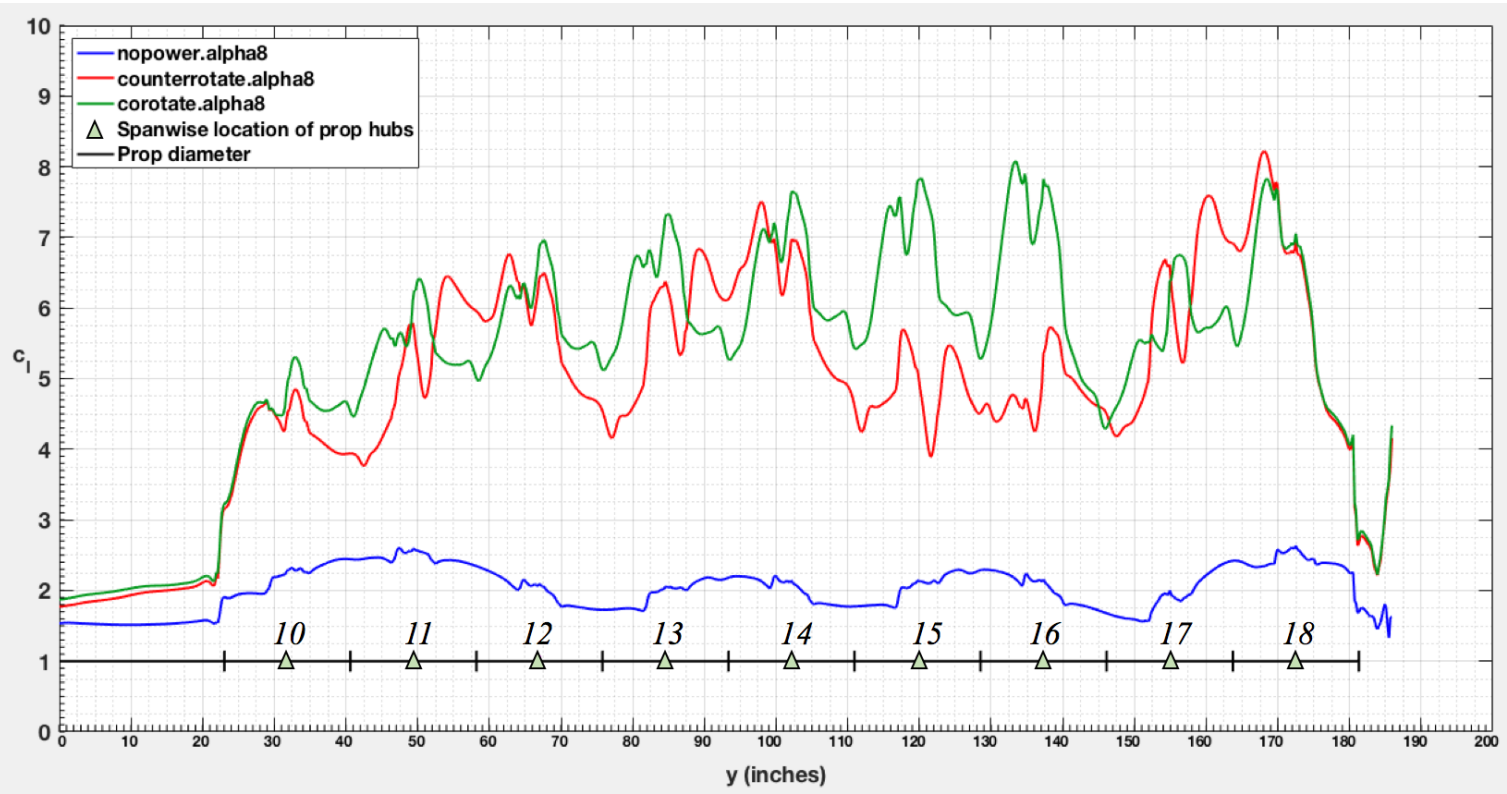

(c) $\quad \alpha=8^{\circ}$

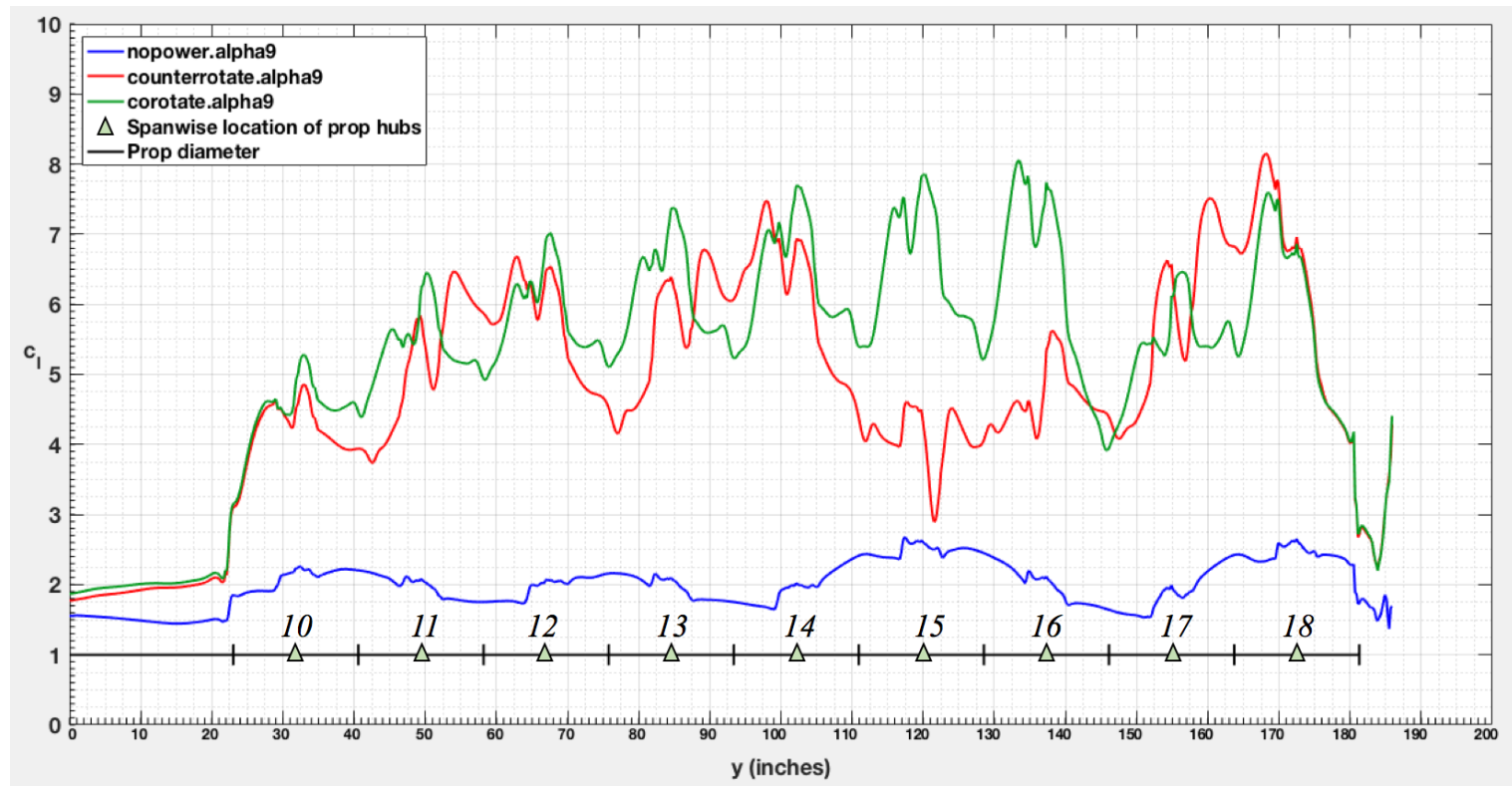

(d) $\quad \alpha=9^{\circ}$

Figure 6 Continued. The effect of propeller spin direction approach on spanloading at four angles of attack for the blown, high-lift wing $\left(40^{\circ}\right.$ flap) at $73 \mathrm{mph}, M=0.096, R e=1$ million, $\mathrm{h}=2300 \mathrm{ft}, \mathrm{T}=60^{\circ} \mathrm{F}$, and $300.6 \mathrm{hp}$ (16.7 hp/prop, $6147 \mathrm{RPM})$. 


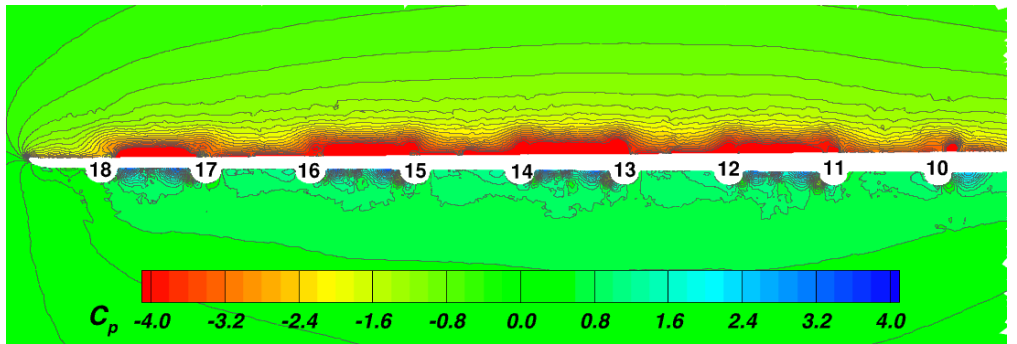

(a) Counter-rotating propellers

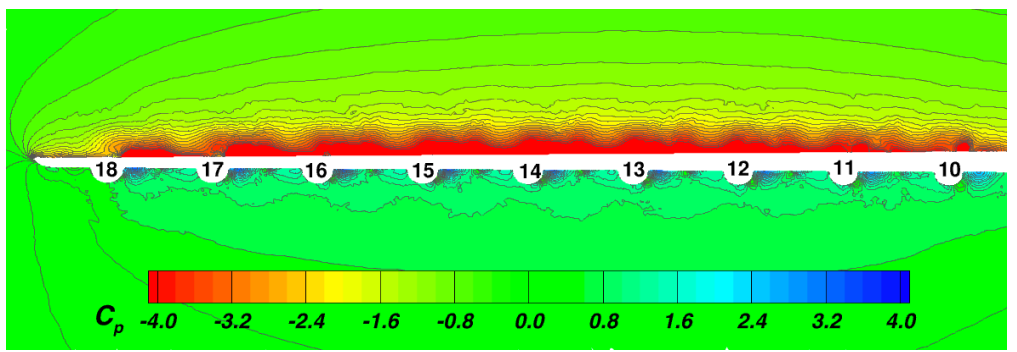

(b) Corotating propellers

Figure 7. The comparison of pressure coefficient on a spanwise plane between approaches to propeller spin direction for the blown, high-lift wing $\left(40^{\circ}\right.$ flap) at $73 \mathrm{mph}, M=0.096, \alpha=4^{\circ}, \operatorname{Re}=1 \mathrm{million}, \mathrm{h}=$ $2300 \mathrm{ft}, \mathrm{T}=60^{\circ} \mathrm{F}$, and $300.6 \mathrm{hp}(16.7 \mathrm{hp} / \mathrm{prop}, 6147 \mathrm{RPM})$.

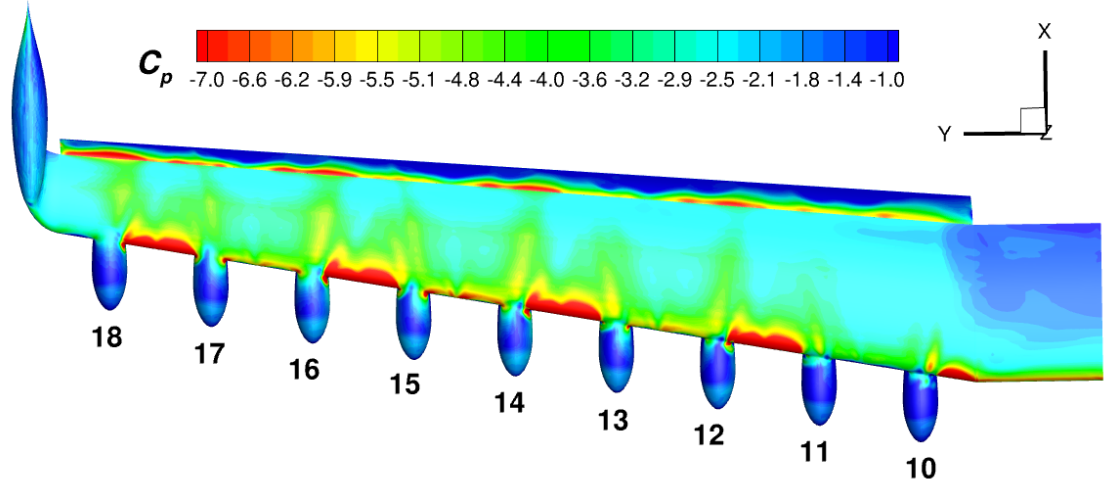

(a) Counter-rotating propellers

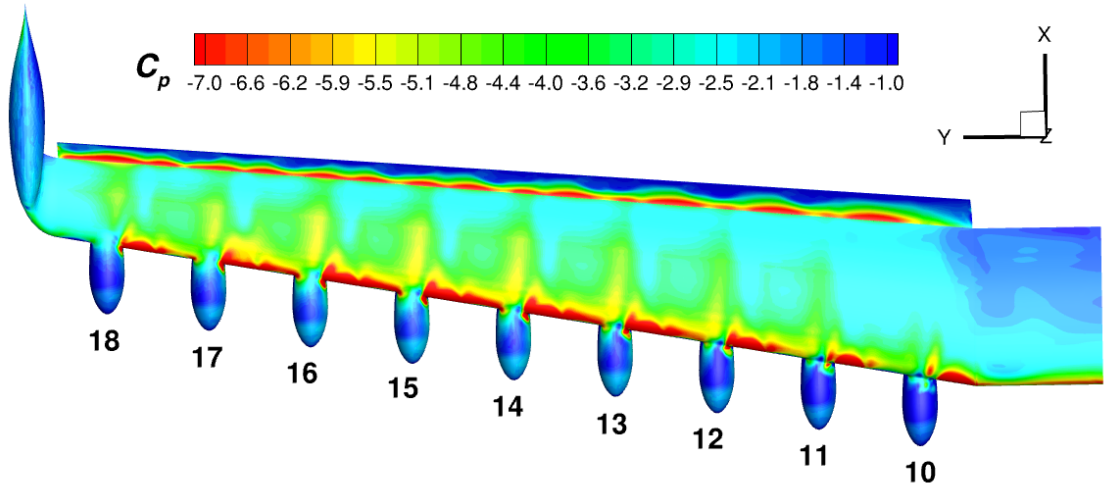

(b) Corotating propellers

Figure 8. The comparison of pressure coefficient on the wing upper surface between approaches to propeller spin direction for the blown, high-lift wing $\left(40^{\circ}\right.$ flap $)$ at $73 \mathrm{mph}, M=0.096, \alpha=4^{\circ}, R e=1$ million, $\mathrm{h}=2300 \mathrm{ft}, \mathrm{T}=60^{\circ} \mathrm{F}$, and $300.6 \mathrm{hp}(16.7 \mathrm{hp} / \mathrm{prop}, 6147 \mathrm{RPM})$. 
Denver, CO

\begin{tabular}{|l|l|l|l|}
\hline Propellers Operating & $C_{L}$ & $C_{D}$ & $C_{m}$ \\
\hline 10 to 18 (all) & 6.422 & 1.645 & -5.728 \\
\hline 10 to 15 & 5.020 & 1.414 & -4.029 \\
\hline $12,14,16,18$ (even) & 4.574 & 1.302 & -4.102 \\
\hline 11 to 16 & 5.004 & 1.407 & -4.375 \\
\hline
\end{tabular}

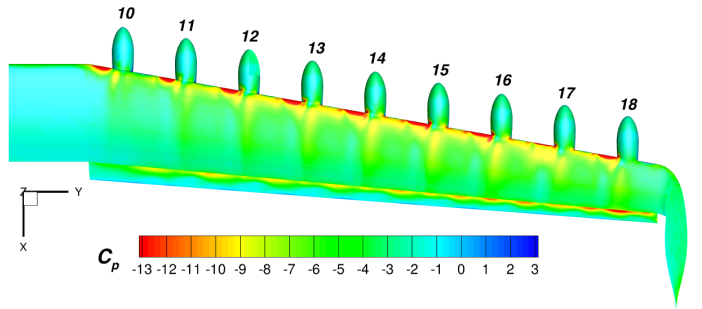

(a) Propellers 10 to 18 (all)

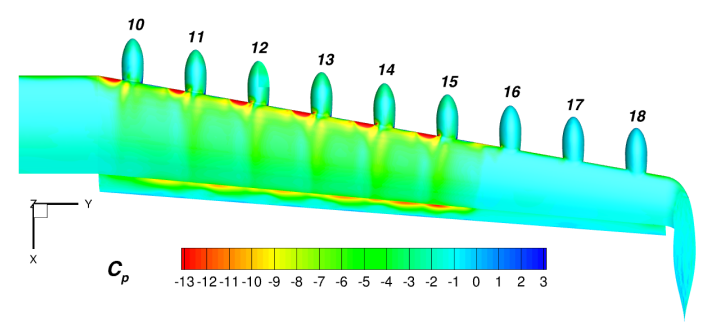

(b) Propellers 10 to 15

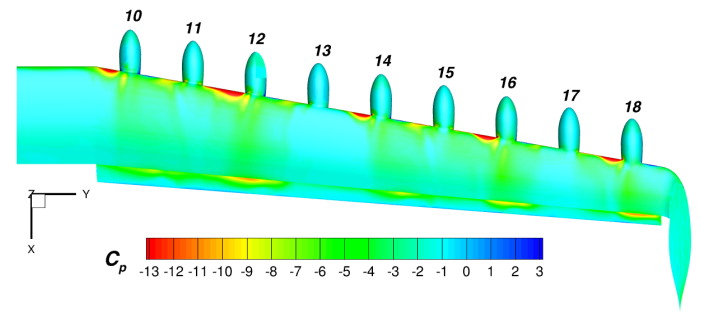

(c) Propellers 12, 14, 16, 18 (even)

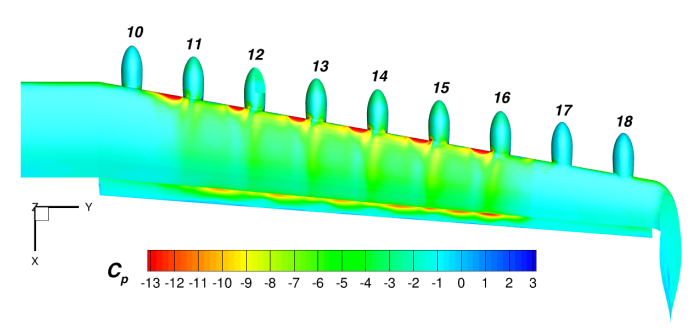

(d) Propellers 11 to 16

Figure 9. The pressure coefficient on the upper wing surface at $60 \mathrm{mph}, M=0.079, \alpha=4^{\circ}, R e=0.82$ million, $h=2300 \mathrm{ft}$, and $\mathrm{T}=\mathbf{6 0}^{\circ} \mathrm{F}$ for various corotating propellers blowing for lift augmentation using $16.7 \mathrm{hp} /$ prop at $6,771 \mathrm{RPM}$. 


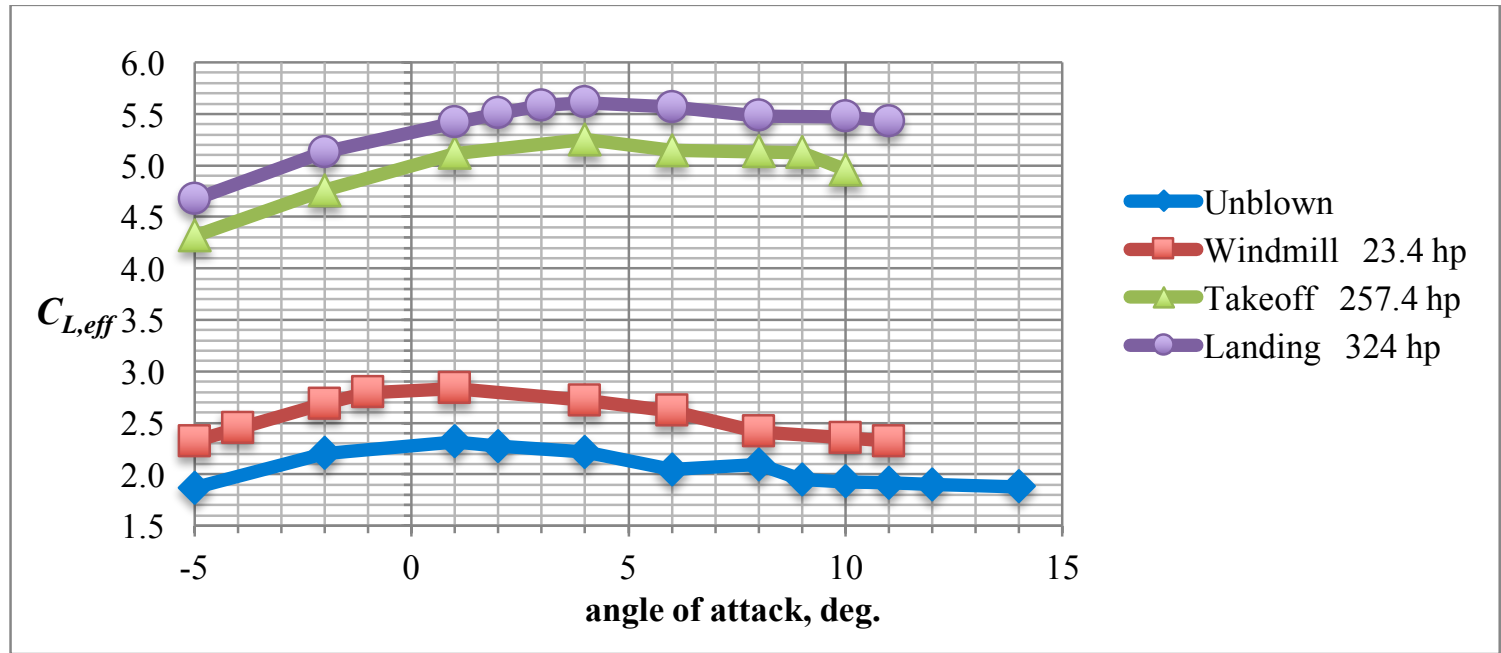

(a) lift coefficient

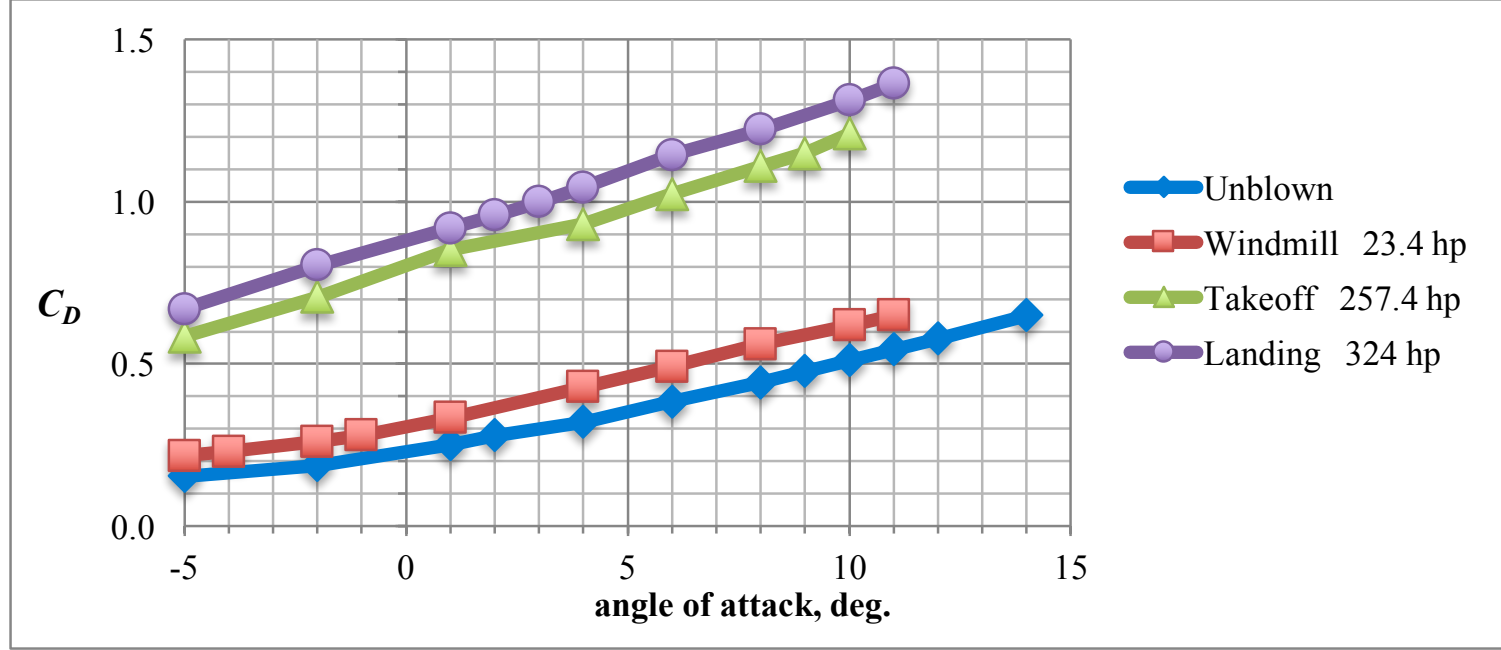

(b) drag coefficient

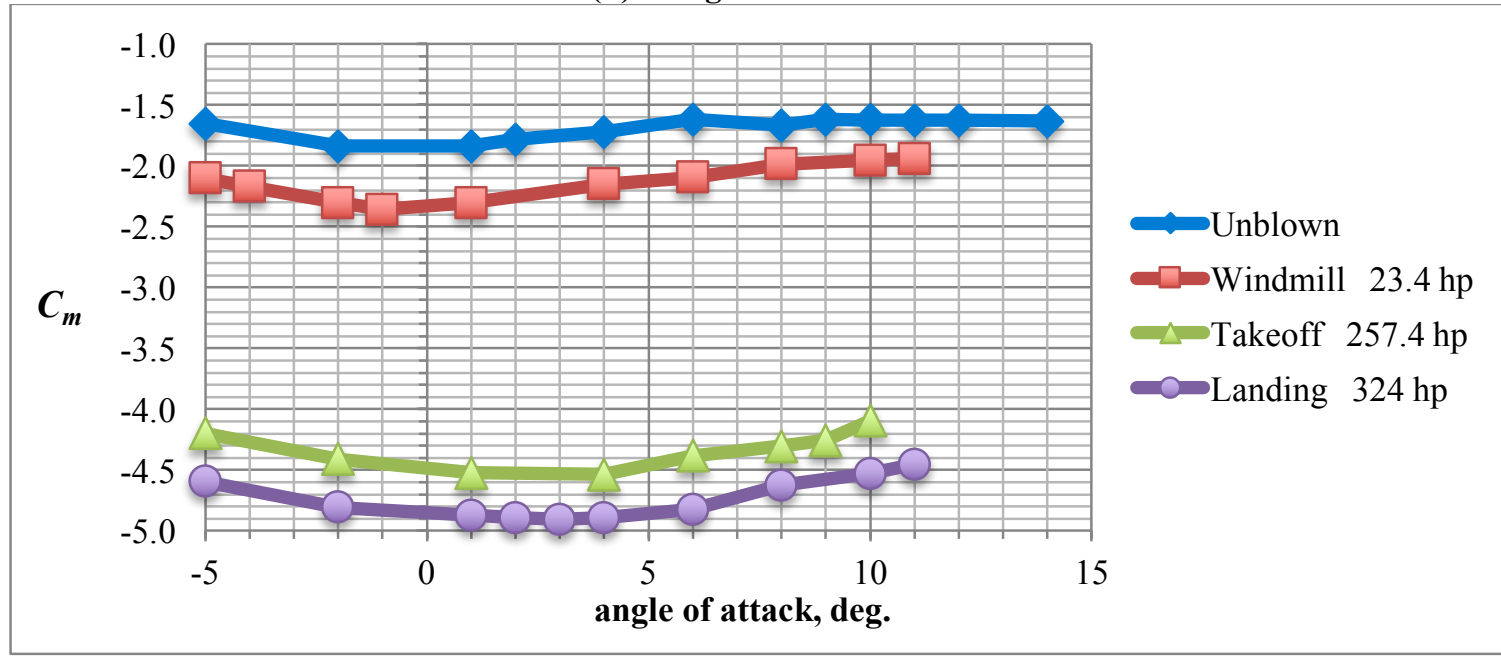

(c) pitching moment coefficient

Figure 10. The lift, drag and pitching moment coefficients for the high-lift wing $\left(40^{\circ}\right.$ flap) at $73 \mathrm{mph}$, $M=0.098, R e=1.07$ million, $h=2300 \mathrm{ft}$, and $\mathrm{T}=40^{\circ} \mathrm{F}$. The blown wing was computed with 3 power settings using corotating propellers. 


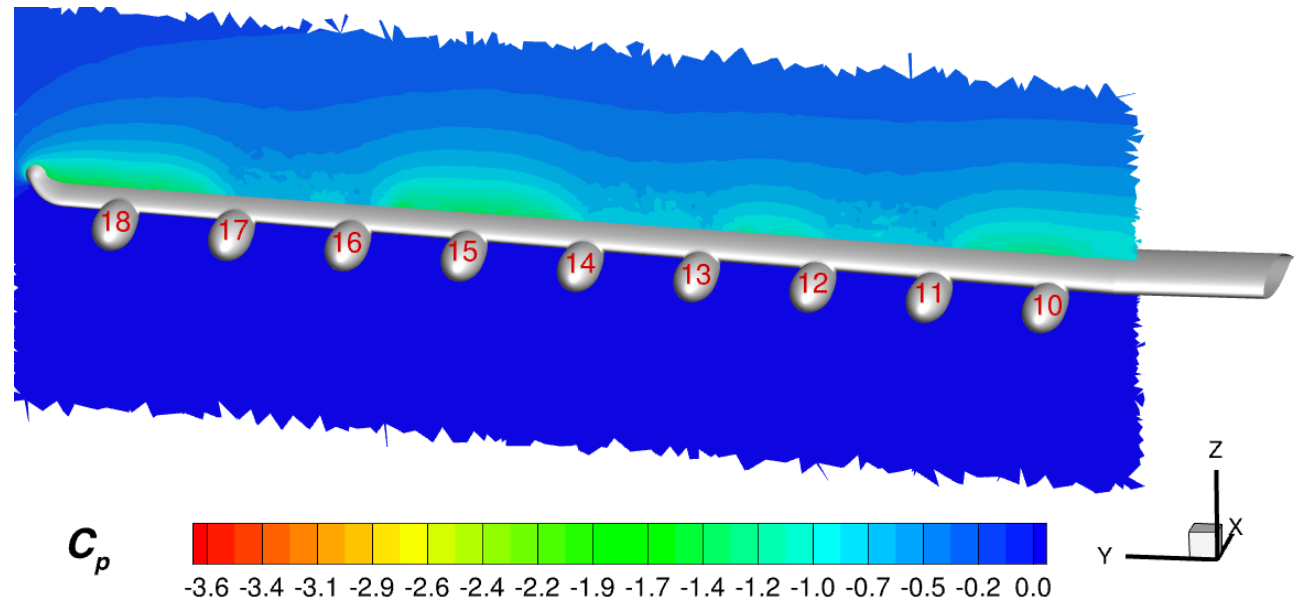

(a) Unblown

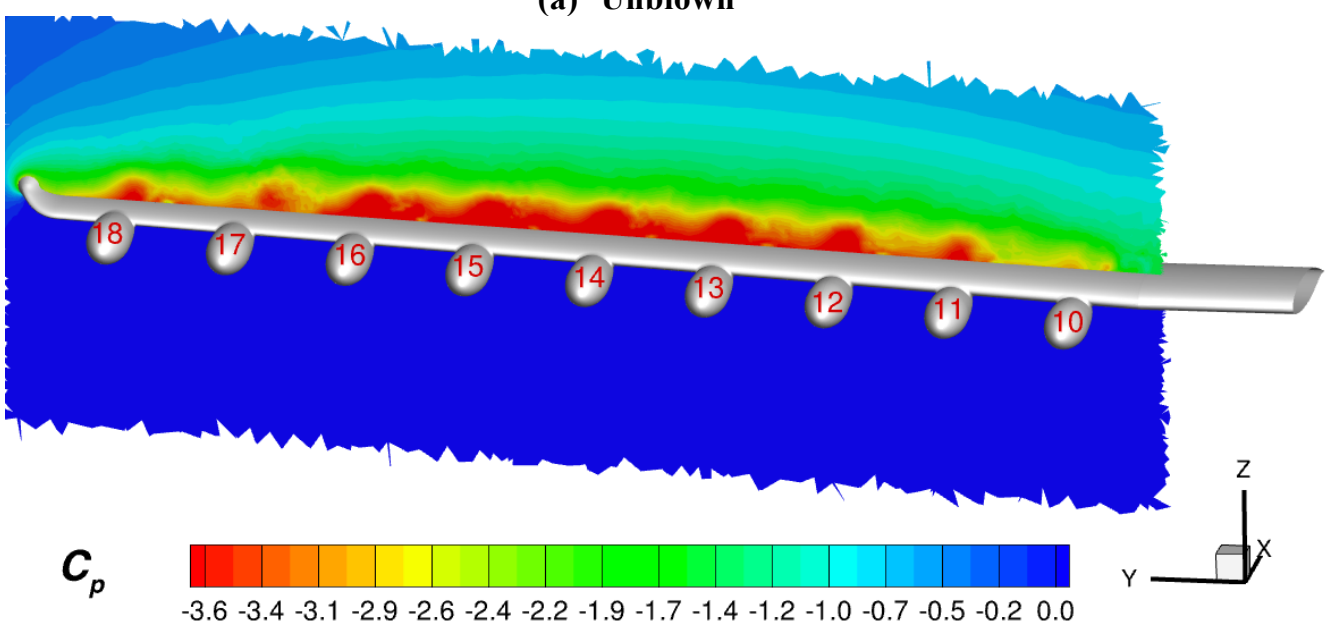

(b) Corotating, takeoff power $257.4 \mathrm{hp}(14.3 \mathrm{hp} /$ prop, $6370 \mathrm{RPM})$

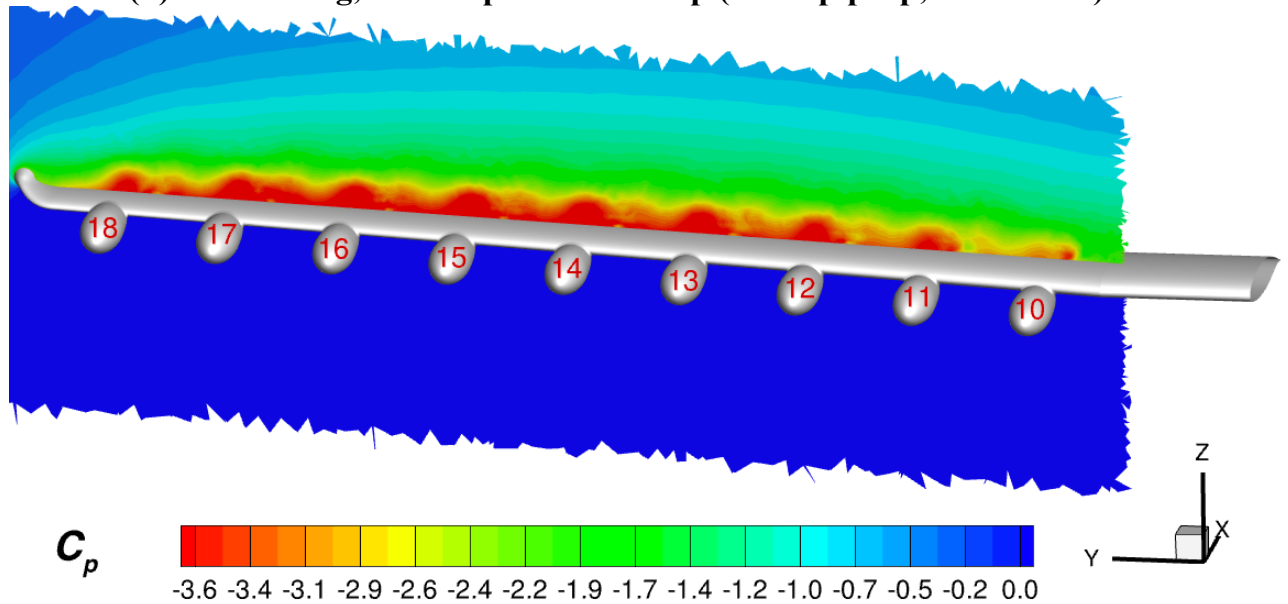

(c) Corotating, landing power $324 \mathrm{hp} \mathrm{(18} \mathrm{hp/prop,} 6860 \mathrm{RPM})$

Figure 11. Comparison of pressure coefficient between the unblown wing, the blown-wing with corotating takeoff power, and the blown-wing with corotating landing power high-lift wing ( $40^{\circ}$ flap) at $73 \mathrm{mph}, M=0.098, \alpha=4^{\circ}, R e=1.07$ million, $\mathrm{h}=2300 \mathrm{ft}$, and $\mathrm{T}=40^{\circ} \mathrm{F}$. 


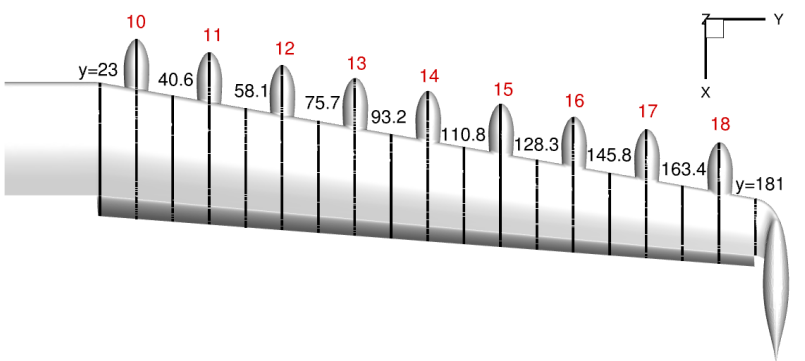

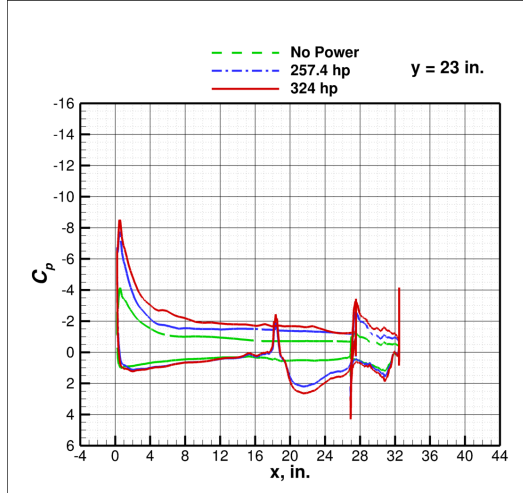

(a) $y=23$ in.

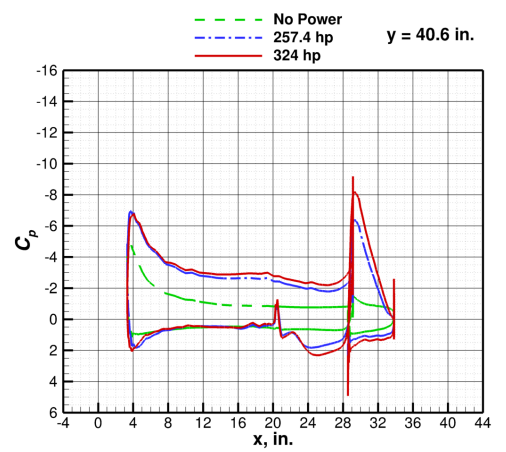

(b) $y=40.6$ in.

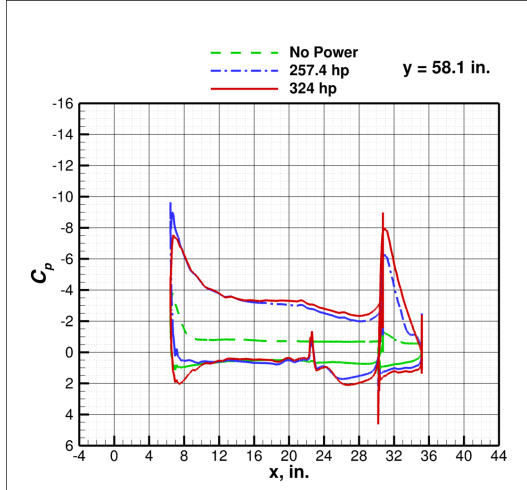

(c) $\mathbf{y}=\mathbf{5 8 . 1}$ in.

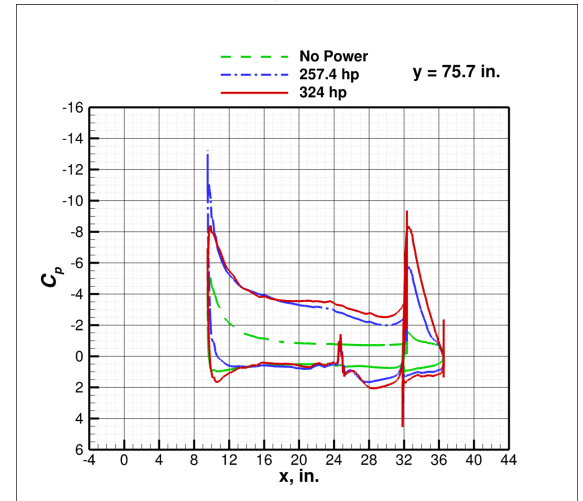

(d) $\mathbf{y}=\mathbf{7 5 . 7} \mathrm{in}$.

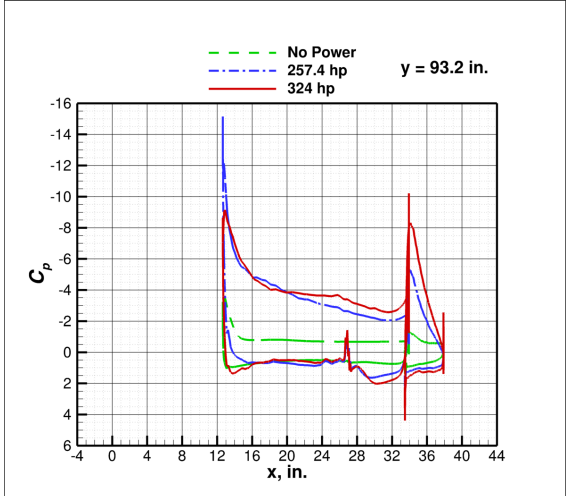

(e) $y=93.2$ in.

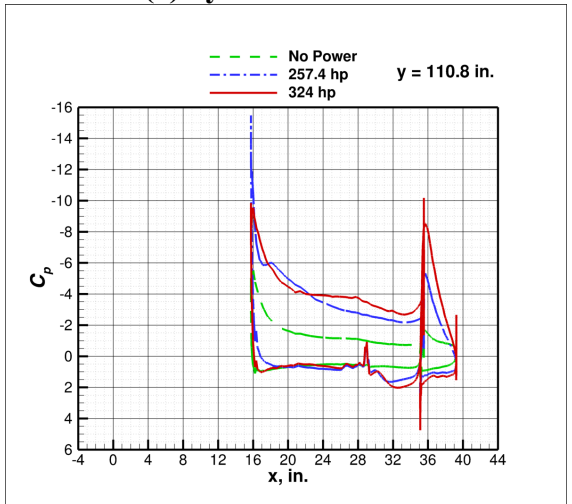

(f) $y=110.8$ in.

Figure 12. Pressure coefficient for the high-lift wing $\left(40^{\circ}\right.$ flap $)$ at $73 \mathrm{mph}, M=0.098, \alpha=4^{\circ}, R e=1.07$ million, $h=2300 \mathrm{ft}$, and $\mathrm{T}=40^{\circ} \mathrm{F}$. 


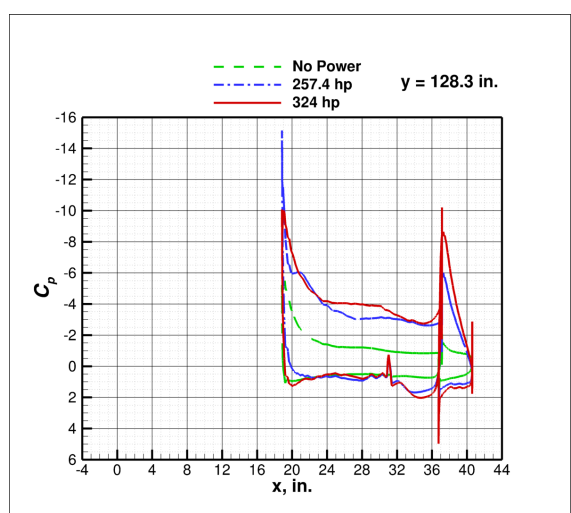

(g) $y=128.3$ in.

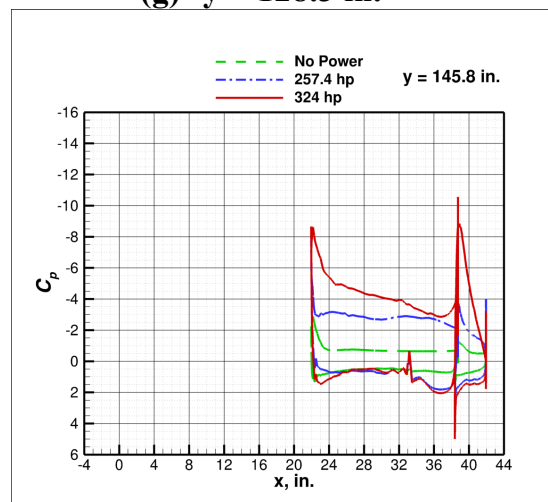

(h) $y=145.8$ in.

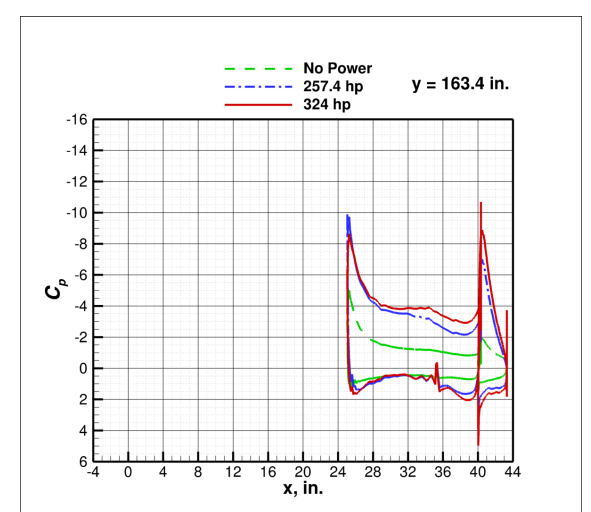

(i) $y=163.4$ in.

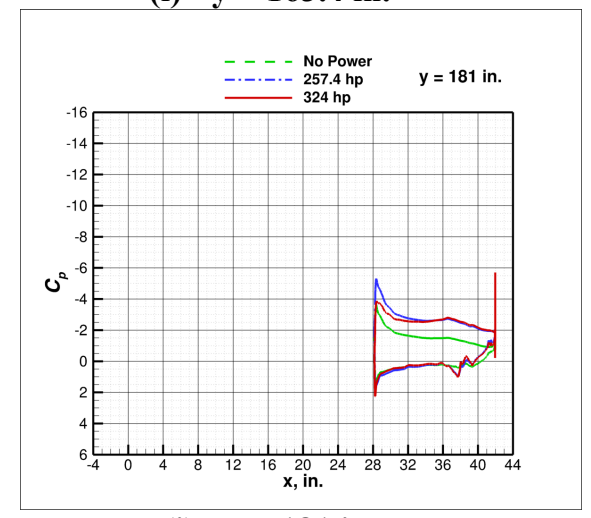

(j) $y=181$ in.

Figure 12 Continued. Pressure coefficient for the high-lift wing $\left(40^{\circ}\right.$ flap $)$ at $73 \mathrm{mph}, M=0.098, \alpha=4^{\circ}$, $R e=1.07$ million, $\mathrm{h}=\mathbf{2 3 0 0} \mathrm{ft}$, and $\mathrm{T}=40^{\circ} \mathrm{F}$.

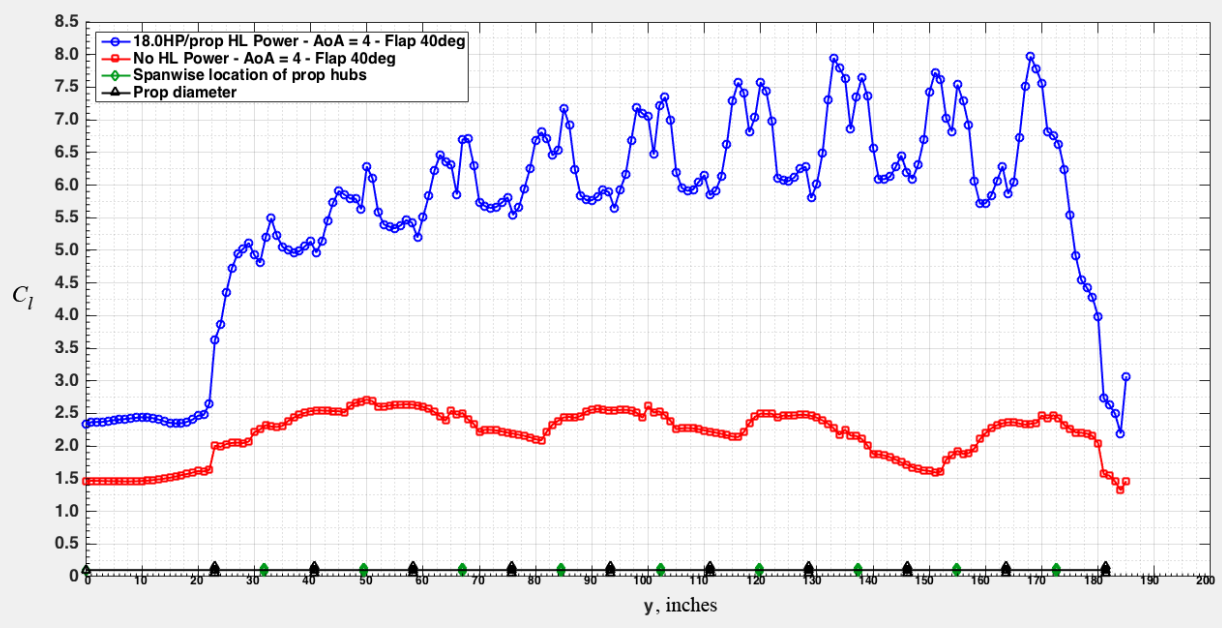

Figure 13. Comparison of spanwise lift coefficient between the unblown high-lift wing $\left(40^{\circ}\right.$ flap $)$ and the blown-high-lift wing $\left(40^{\circ}\right.$ flap) with corotating propellers at landing power $(324 \mathrm{hp}, 18 \mathrm{hp} / \mathrm{prop}$, $6860 \mathrm{RPM}$ ) at $73 \mathrm{mph}, M=0.098, \alpha=4^{\circ}, R e=1.07$ million, $\mathrm{h}=2300 \mathrm{ft}$, and $\mathrm{T}=40^{\circ} \mathrm{F}$. 